\title{
The Effect of Relative Humidity on Maritime Tropical Aerosols
}

\author{
Bello Idrith Tijjani' ${ }^{1}$, Fatima Sha'aibu' ${ }^{2}$, Aliyu Aliyu ${ }^{3}$ \\ ${ }^{1}$ Department of Physics, Bayero University, Kano, Nigeria \\ ${ }^{2}$ Girl's Science and Technical College, Kano, Nigeria \\ ${ }^{3}$ Department of Science Laboratory Technology, School of Technology, Kano State Polytechnic, Kano, Nigeria \\ Email: idrith@yahoo.com, idrithtijiani@gmail.com
}

Received 22 March 2014; revised 26 April 2014; accepted 2 May 2014

Copyright (C) 2014 by authors and Scientific Research Publishing Inc.

This work is licensed under the Creative Commons Attribution International License (CC BY). http://creativecommons.org/licenses/by/4.0/

c) (i) Open Access

\begin{abstract}
The present work focused on the effect of relative humidity $(R H)$ on some microphysical and optical properties of maritime tropical aerosols from the software package OPAC (Optical Properties of Aerosols and Clouds) data at the spectral range of $0.25 \mu \mathrm{m}$ to $2.5 \mu \mathrm{m}$ and eight relative humidities $(0 \%, 50 \%, 70 \%, 80 \%, 90 \%, 95 \%, 98 \%$, and $99 \%)$. The microphysical properties extracted were radii, volume mix ratio, number mix ratio and mass mix ratio as a function of $R H$ while the optical properties were optical depth, extinction, scattering and absorption coefficients single scattering albedo, refractive indices and asymmetric parameters. The hygroscopic growth and enhancement parameters were then parameterized by using some models to determine the hygroscopicity, bulk hygroscopicity, humidification factors and some other parameters that depend on $\mathrm{RH}$ and/or wavelengths. The results showed that the data fitted our models very well and can be used to extrapolate the hygroscopic growth at any $R H$ and enhancement parameters at any $R H$ and wavelengths. The importance of determining $g f_{\text {mix }}(R H)$ as a function of $R H$ and volume fractions, mass fractions and number fractions, and enhancement parameters as a function of $R H$. The effective radii increases with the increase in $R H$, while Angstrom coefficients decrease with the increase in $R H$ and this signifies the dominance of coarse mode particles. The angstrom coefficients show that the mixture has bimodal type of distribution and the mode size increases with the increase in $R H$.
\end{abstract}

\section{Keywords}

Microphysical Properties, Optical Properties, Hygroscopic Growth, Parametrization, Enhancement Parameters, Angstrom Coefficients, Effective Refractive Indices 


\section{Introduction}

Atmospheric aerosol particles reveal changes in their microphysical and optical characteristics with their ambient relative humidity $(R H)$ due to the water uptake [1]-[3]. Since atmospheric aerosols are far from being a single component, the question is how relative humidity influences the optical properties of natural aerosol mixtures, which can contain both soluble and insoluble components. These hygroscopic atmospheric aerosols undergo droplet growth, evaporation and phase transformation from a solid particle to a saline droplet which usually occurs spontaneously when the $R H$ reaches a level called the deliquescence humidity. Its value is specific to the chemical composition of the aerosol particle [4] [5]. Ambient aerosols generally composed of external and internal mixtures of particles with different chemical compounds, chemical compositions and physical properties such as soot, sulphate, nitrate, organic carbon and mineral dust. The state of mixing of these components is crucial for understanding the role of aerosol particles in the atmosphere.

The hygroscopicity of these aerosol particles plays an important role in the atmosphere, because they influence the radiative budget of the earth directly by scattering and absorbing the incoming sunlight and indirectly by serving as cloud condensation nuclei for the formation of fog and cloud droplets [6]. Depending on the chemical composition, aerosol particles can take up large amounts of water compared to their dry state as relative humidity increases to $100 \%$ and thus radically increase their size and change their optical properties [7]. The aerosol hygroscopic properties are very crucial for the understanding of the aerosol effects on climate via their effects on clouds, since the hygroscopic growth measured at sub saturation is closely related to the ability of aerosol particles to activate and form cloud droplets [8] [9]. Changes in particle size and phase with relative humidity modify heterogeneous atmospheric chemistry, cloud and fog formation processes, and visibility. As climate models improve, they must incorporate the dependence of aerosol radiative effects on $R H$. Because of the important role that water vapor plays in determining aerosol effects, it is critical to develop the understanding that is required to reliably represent water vapor-particle interactions in models.

The Kohler Equation is often used to describe both the hygroscopic growth and the activation of aerosol particles to cloud droplets, based on the aerosol's physicochemical properties [10]. However, these detailed properties are not always available for ambient aerosols. Size-dependent mixing states of various chemical compositions also increase the complexity. Recently, several single-parameter schemes have been proposed to simplify the Kohler Equation. Hygroscopicity parameters such as $\kappa$ and pion have been defined as proxies of chemical composition to represent aerosol hygroscopic growth as well as the ability of aerosol particles to become cloud condensation nuclei (CCN) [11] [12]. Moreover, Rissler et al. [9] recently overviewed several models which describe the aerosol hygroscopicity and the CCN activation.

Hygroscopic properties of aerosol particles were investigated in marine environments in several field studies in the last ten years [13]-[15]. Based on a review of observational data, Andreae and Rosenfeld [16] suggested that continental and marine aerosols on average tend to cluster into relatively narrow ranges of effective hygroscopicity (continental $\kappa=0.3 \pm 0.1$; marine $\kappa=0.7 \pm 0.2$ ). Recent field studies are largely consistent with this view, but they show also systematic deviations for certain regions and conditions. For example, Gunthe et al. [17] reported a characteristic value of $\kappa=0.15$ for pristine tropical rainforest aerosols in central Amazonia, which are largely composed on secondary organic matter.

Sea salt aerosols are also of interest since they are the dominant kind by mass over the oceans [18] [19].

The main parameter used to characterize the hygroscopicity of the aerosol particles is the aerosol hygroscopic growth factor $\mathrm{GF}(R H)$, which is defined as the ratio of the particle diameter at any $R H$ to the particle diameter at $R H=0 \%[8]$ [20].

Changes in the aerosol optical properties resulting from the particle hygroscopic growth are described by enhancement factors $\mathrm{f}(R H)$, which, for each optical parameter $\chi$, are defined as the ratio between its values determined in any conditions $\chi(R H)$ and those determined in dry conditions $\chi(R H=0 \%)$. Technically, the enhancement factor for scattering and hemispherical backscattering can be determined for a chosen $R H$ by using two nephelometers performing measurements at the chosen $R H$ and in dry conditions ( $R H=0 \%$ ), respectively [21][26]

The aim of this study is to determine the aerosols hygroscopic growth and enhancement factors for maritime tropical aerosols from the data extracted from OPAC. One and two variables parameterizations models will be performed to determine the relationship of the particles' hygroscopic growth and enhancement parameters with the $R H$. Angstrom coefficients are used to determine the particles' type and the type mode size distributions. 


\section{Methodology}

The models extracted from OPAC are given in Table 1.

Where water soluble components consists of scattering aerosols, that are hygroscopic in nature, such as sulfates and nitrates present in anthropogenic pollution, while sea-salt accumulation and coarse modes are two kinds of salt contained in seawater that are more hygroscopic than water soluble.

The software package OPAC is written in FORTAN programming language. It easily provides optical properties in the solar and terrestrial spectral range of atmospheric particulate matter. Microphysical and optical properties of ten (10) aerosol components, which are considered as typical cases, are stored as ASCII files. The optical properties of the aerosols are calculated on the basis of the microphysical data (size distribution and spectral refractive index) under the assumption of spherical particles. Data are given for up to 61 wavelengths between 0.25 and $40 \mu \mathrm{m}$ and up to eight values of the relative humidity.

The globally averaged direct aerosol Radiative forcing, $\Delta F_{R}$, for absorbing aerosols was calculated using the equation derived by Chylek and Wong [28] as:

$$
\Delta F_{R}=-\frac{S_{0}}{4} T_{a t m}^{2}(1-N)\left\{(1-A)^{2} 2 \beta \tau_{s c a}-4 A \tau_{a b s}\right\}
$$

where $S_{0}$ is a solar constant, $T_{a t m}$ is the transmittance of the atmosphere above the aerosol layer, $N$ is the fraction of the sky covered by clouds, $A$ is the albedo of underlying surface, $\beta$ is the upscattering fraction of radiation scattered by aerosol into the atmosphere while $\tau_{\text {sca }}$ and $\tau_{a b s}$ are the aerosol layer scattering and absorptions optical thickness respectively. The above expression gives the radiative forcing due to the change of reflectance of the earth-aerosol system. The upscattering fraction is calculated using an approximate relation [29]

$$
\beta=\frac{1}{2}(1-g)
$$

where $g$ is the asymmetric parameter. The global averaged albedo $A=0.22$ over land and $A=0.06$ over the ocean with $80 \%$ of aerosols being over the land; solar constant of $1370 \mathrm{Wm}^{-2}$, the atmospheric transmittance is taken to be $T_{a t m}=0.79[30]$ and cloudness $N=0.6$.

The aerosol's hygroscopic growth factor $g f(R H)$, [8] [31] is defined as:

$$
g f(R H)=\frac{D(R H)}{D(R H=0)}
$$

where $R H$ is taken for seven values 50\%, 70\%, 80\%, 90\%, 95\%, 98\% and 99\%.

But since atmospheric aerosols consist of more and less hygroscopic sub fractions so the information on the hygroscopicity modes was merged into an "over-all" or "bulk" hygroscopic growth factor of the mixture, $g f_{\text {mix }}(R H)$, representative for the entire particle population as:

$$
g f_{\text {mix }}(R H)=\left(\sum_{k} x_{k} g f_{k}^{3}\right)^{1 / 3}
$$

The effective or volume equivalent radius of the mixture was determined using the relation

$$
r_{\text {eff }}(R H)=\left(\sum_{k} x_{k} r_{k}^{3}\right)^{1 / 3}
$$

Table 1. Compositions of aerosols types at $0 \% R H$ [27].

\begin{tabular}{cccccc}
\hline Components & No.Conc. $\left(\mathbf{c m}^{-3}\right)$ & $\boldsymbol{R}_{\min }(\boldsymbol{\mu m})$ & $\boldsymbol{R}_{\max }(\boldsymbol{\mu m})$ & Sigma & $\boldsymbol{R}_{\text {mod }}(\boldsymbol{\mu m})$ \\
Water soluble & 590.0000 & 0.0050 & 20.0000 & 2.2400 & 2.0300 \\
Sea-salt accumulation & 10.0000 & 0.0050 & 0.000 & 2090 \\
Sea-salt coarse modes & 0.0013 & 0.0050 & 60.0000 & 2.0300 \\
\hline
\end{tabular}


where the summation is performed over all compounds present in the particles and $x_{k}$ represent their respective volume fractions, using the Zdanovskii-Stokes-Robinson relation [32]-[35]. Solute-solute interactions are neglected in this model and volume additivity is also assumed. The model assumes spherical particles, ideal mixing (i.e. no volume change upon mixing) and independent water uptake of the organic and inorganic components.

Equations (4) and (5) can also be computed using the $x_{k}$ as the corresponding number fractions [36] [37].

We now proposed the $x_{k}$ to represent the mass mix ratio of the individual particles.

The $R H$ dependence of $g f_{\text {mix }}(R H)$ can be parameterized in a good approximation by a one-parameter equation, proposed e.g. by Petters and Kreidenweis [11] as:

$$
g f_{\text {mix }}\left(a_{w}\right)=\left(1+\kappa \frac{a_{w}}{1-a_{w}}\right)^{\frac{1}{3}}
$$

Here, $a_{w}$ is the water activity, which can be replaced by the relative humidity $R H$, if the Kelvin effect is negligible, as for particles with sizes more relevant for light scattering and absorption. The coefficient $\kappa$ is a simple measure of the particle's hygroscopicity and captures all solute properties (Raoult effect), that is, it is for the ensemble of the particle which can be defined in terms of the sum of its components. In an ensemble of aerosol particles, the hygroscopicity of each particle can be described by an "effective" hygroscopicity parameter $\kappa$ [11] [38]. Here "effective" means that the parameter accounts not only for the reduction of water activity by the solute but also for surface tension effects [17] [39] [40]. It also scales the volume of water associated with a unit volume of dry particle [11] and depends on the molar volume and the activity coefficients of the dissolved compounds [41]. The $\kappa$ value derived a particle of a given composition may vary, depending upon the size molar mass, the activity and $R H$ it is derived at.

For atmospheric aerosols, the range of $\kappa$ typically varies from as low as $\sim 0.01$ for some combustion aerosol particles up to $\sim 1$ for sea-salt particles [11] [16] [42] [43].

The following sub-divisions at 85\% $R H$ were made by Swietlicki et al., [8] and Liu et al., [44]; as nearly-hydrophobic particles $(N H): \kappa<=0.10\left(g f_{\text {mix }}<=1.21\right)$, less-hygroscopic particles $(L H): \kappa=0.10-0.20\left(g f_{\text {mix }}=1.21-\right.$ 1.37); more-hygroscopic particles $(M H): \kappa>0.20\left(g f_{\text {mix }}>1.37\right)$.

Making $\kappa$ as the subject of Equation (6), we get

$$
k\left(a_{w}\right)=\frac{\left[g f_{\text {mix }}^{3}\left(a_{w}\right)-1\right]\left(1-a_{w}\right)}{a_{w}}
$$

Humidograms of the ambient aerosols obtained in various atmospheric conditions showed that $g f_{\text {mix }}(R H)$ could as well be fitted well with a $\gamma$-law [14] [45]-[48] as;

$$
g f_{\text {mix }}(R H)=(1-R H)^{\gamma}
$$

Making $\gamma$ as the subject of Equation (8) we get

$$
\gamma(R H)=\frac{\ln \left(g f_{\text {mix }}(R H)\right)}{\ln (1-R H)}
$$

The bulk hygroscopicity factor $B$ under subsaturation $R H$ conditions was determined using the relation:

$$
B=\left(1-g f_{\text {mix }}^{3}\right) \ln a_{w}
$$

where $a_{w}$ is the water activity, which can be replaced by the $R H$ as explained before.

The impact of hygroscopic growth on the optical properties of aerosols is usually described by the enhancement factor $f_{\chi}(R H, \lambda)$ :

$$
f_{\chi}(R H, \lambda)=\frac{\chi(R H, \lambda)}{\chi\left(R H_{r e f}, \lambda\right)}
$$

where in our study $R H_{\text {ref }}$ was $0 \%$, and $R H$ was taken for seven values of $50 \%, 70 \%, 80 \%, 90 \%, 95 \%, 98 \%$ and 
$99 \%$.

In general, the relationship between $f_{\chi}(R H, \lambda)$ and $R H$ is nonlinear [49]. In this paper, we determine the empirical relations between the enhancement parameter and $R H$ [50] as:

$$
f_{\chi}(R H, \lambda)=\frac{\chi(R H, \lambda)}{\chi\left(R H_{r e f}, \lambda\right)}=\left(\frac{100-R H_{r e f}}{100-R H}\right)^{\gamma}
$$

The $\gamma$ known as the humidification factor represents the dependence of aerosol optical properties on $R H$, which results from the changes in the particles sizes and refractive indices upon humidification. The use of $\gamma$ has the advantage of describing the hygroscopic behavior of aerosols in a linear manner over a broad range of $R H$ values; it also implies that particles are deliquesced [51], a reasonable assumption for this data set due to the high ambient relative humidity during the field study. The $\gamma$ parameter is dimensionless, and it increases with increasing particle water uptake.

Making $\gamma$ as the subject of Equation (12) and $R H_{\text {ref }}=0$, we get

$$
\gamma(R H, \lambda)=-\frac{\ln \left(f_{\chi}(R H, \lambda)\right)}{\ln (1-R H)}
$$

From previous studies, typical values of $\gamma$ for ambient aerosol ranged between 0.1 and 1.5 [51]-[53].

Two parameters empirical relation was also used [49] [54] as;

$$
f_{\chi}(R H, \lambda)=a(1-R H)^{b}
$$

Equations (12) and (14) are verified at wavelengths 0.25, 0.45, 0.55, 0.70, 1.25, and $2.50 \mu \mathrm{m}$.

To determine the effect of particles distributions as a result of change in $R H$, the Angstrom exponent was determined using the spectral behavior of the aerosol optical depth, with the wavelength of light $(\lambda)$ was expressed as inverse power law [55]:

$$
\tau(\lambda)=\beta \lambda^{-\alpha}
$$

The Angstrom exponent was obtained as a coefficient of the following regression,

$$
\ln \tau(\lambda)=-\alpha \ln (\lambda)+\ln \beta
$$

However, Equation (16) was determined as non-linear (that is the Angstrom exponent itself varies with wavelength), and a more precise empirical relationship between the optical depth and wavelength was obtained with a 2nd-order polynomial [56]-[66] as:

$$
\operatorname{lnt}(\lambda)=\alpha_{2}(\ln \lambda)^{2}+\alpha_{1} \ln \lambda+\ln \beta
$$

and then we proposed the cubic relation to determine the type of mode distribution as:

$$
\ln \mathrm{X}(\lambda)=\ln \beta+\alpha_{1} \ln \lambda+\alpha_{2}(\ln \lambda)^{2}+\alpha_{3}(\ln \lambda)^{3}
$$

where $\beta, \alpha, \alpha_{1}, \alpha_{2}, \alpha_{3}$ are constants that were determined using regression analysis with SPSS16.0. forwondows.

We also determined the exponential dependence of the aerosol optical thickness on relative humidity as done by Jeong et al. [49]as;

$$
\tau(R H)=A e^{B(R H / 100)}
$$

where $A$ and $B$ are constants determined using regression analysis with SPSS 16.0 and was computed at wavelengths $0.25,1.25$ and $2.50 \mu \mathrm{m}$.

We finally determine the effect of hygroscopic growth on the effective refractive indices of the mixed aerosols using the following formula [67]:

$$
\frac{\varepsilon_{\text {eff }}-\varepsilon_{0}}{\varepsilon_{\text {eff }}+2 \varepsilon_{0}}=\sum_{i} f_{i} \frac{\varepsilon_{i}-\varepsilon_{0}}{\varepsilon_{i}+2 \varepsilon_{0}}
$$


The relation between dielectrics and refractive indices is

$$
m_{i}=\sqrt{\varepsilon_{i}}
$$

We also used another mixing rule formula that has been used in the several widely employed databases of aerosol optical properties [27] [68]-[71] as:

$$
m=\sum_{i} f_{i} m_{i}
$$

where $f_{i}$ and $\varepsilon_{i}$ are the volume fraction and dielectric constant of the $i^{\text {th }}$ component and $\varepsilon_{0}$ is the dielectric constant of the host material. For the case of Lorentz-Lorentz [72] [73], the host material is taken to be vacuum, $\varepsilon_{0}$ $=1$.

We then proposed the $f_{i}$ to be mass mix ratios and number mix ratios, to determine the advantage of one over the other.

The computations of Equations (20), (21) and (22) were done using the complex functions of Microsoft Excel 2010.

\section{Results and Discussions}

\subsection{Radiative Forcing}

From Figure 1, at $0 \% R H$ the $R F$ is almost constant with a value of $-5 \mathrm{Wm}^{-2}$ with respect to wavelengths. As the $R H$ increases, the $R F$ (cooling) increases with the increase in $R H$, but become non-linear with respect to wavelengths. At higher $R H$ s the increase in $R F$ (cooling) is more at larger wavelengths than shorter wavelengths. This shows the dominance of coarse mode particles.

\subsection{Microphysical Properties}

From Table 2, it can be observed that there are increases in $g f_{\text {mix }}, r_{\text {eff }}$ and $\gamma$, while there are decreases in $B$ and $\kappa$ with the increase in $R H$.

The results of the parameterizations by one parameter of Equations (6) and (8) using number mix ratios are:

$k=0.1844, R^{2}=0.9549$ from Equation (6);

$\gamma=-0.2146, R^{2}=0.9964$ from Equation (8).

From the observations of $R^{2}$, it can be seen that the data fitted the Equations very well.

From Table 3, it can be observe that there are increases in $g f_{\text {mix }}, r_{\text {eff }}$ and $\gamma$, while there are decreases in $B$ and $\kappa$ with the increase in $R H$.

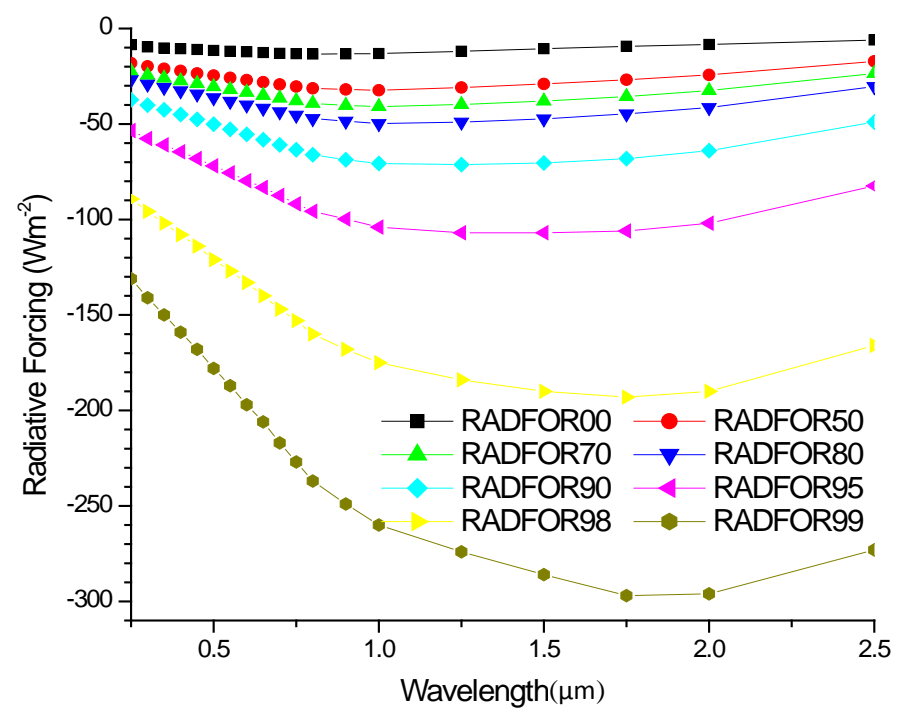

Figure 1. A graph of radiative forcing against wavelengths. 
Table 2. The table of hygroscopic growth factors, effective radii, $B$ (bulk hygroscopicity), $\kappa$ (hygroscopicity) and $\gamma$ (Humidification factor), of the aerosols using number mix ratio.

\begin{tabular}{ccccccccc}
\hline$R H(\%)$ & 0 & 50 & 70 & 80 & 90 & 95 & 98 & 99 \\
\hline$g f_{\text {mix }}(R H)$ Equation (4) & 1.0000 & 1.2439 & 1.3549 & 1.4562 & 1.6598 & 1.9091 & 2.2937 & 2.5968 \\
$r_{\text {eff }}$ Equation (5) & 0.0558 & 0.0888 & 0.0998 & 0.1098 & 0.1310 & 0.1594 & 0.2109 & 0.2620 \\
$B$ Equation (10) & & 0.6411 & 0.5304 & 0.4659 & 0.3764 & 0.3056 & 0.2236 & 0.1660 \\
$\kappa$ Equation (7) & & 0.9249 & 0.6373 & 0.5219 & 0.3969 & 0.3136 & 0.2259 & 0.1668 \\
$\gamma$ Equation (9) & & -0.3149 & -0.2522 & -0.2335 & -0.2201 & -0.2159 & -0.2122 & -0.2072 \\
\hline
\end{tabular}

Table 3. The table of hygroscopic growth factors, effective radii, $B$ (bulk hygroscopicity), $\kappa$ (hygroscopicity) and $\gamma$ (Humidification factor), of the aerosols using volume mix ratio.

\begin{tabular}{cccccccccc}
\hline RH(\%) & 0 & 50 & 70 & 80 & 90 & 95 & 98 & 99 \\
\hline$g f_{\text {mix }}(R H)$ Equation (4) & 1.0000 & 1.5927 & 1.7916 & 1.9718 & 2.3569 & 2.8707 & 3.8040 & 4.7297 \\
$r_{\text {eff }}$ Equation (5) & 0.5606 & 0.7442 & 0.7834 & 0.8164 & 0.8753 & 0.9435 & 1.0606 & 1.1867 \\
$B$ Equation (10) & & 2.1073 & 1.6943 & 1.4876 & 1.2741 & 1.1621 & 1.0919 & 1.0533 \\
$\kappa$ Equation (7) & & 3.0402 & 2.0359 & 1.6667 & 1.3437 & 1.1925 & 1.1030 & 1.0586 \\
$\gamma$ Equation (9) & & -0.6715 & -0.4843 & -0.4219 & -0.3723 & -0.3520 & -0.3415 & -0.3374 \\
\hline
\end{tabular}

The results of the parameterizations by one parameter of Equations (6) and (8) using volume mix ratio are:

$k=1.0740, R^{2}=0.9980$ from Equation (6);

$\gamma=-0.3550, R^{2}=0.9866$ from Equation (8).

From the observations of $R^{2}$, it can be seen that the data fitted the equations very well.

From Table 4, it can be observe that there are increases in $g f_{\text {mix }}, r_{\text {eff }}$ and $\gamma$, while there are decreases in $B$ and $\kappa$ with the increase in $R H$.

The results of the parameterizations by one parameter of Equations (6) and (8) using mass mix ratio are:

$k=1.0731, R^{2}=0.9980$ from Equation (6);

$\gamma=-0.3548, R^{2}=0.9867$ from Equation (8).

From the observations of $R^{2}$, it can be seen that the data fitted the equations very well.

From Figure 2, it can be observed that the plots of $g f_{\text {mix }}$ using mass and volume mix ratios are the same and higher than the $g f_{\text {mix }}$ using number mix ratios. It can also be observed that all the plots satisfy power law.

From Figure 3, it can be observed that the plots of $r_{\text {eff }}$ using mass and volume mix ratios are the same and higher than the $r_{\text {eff }}$ using number mix ratios. It can also be observed that all the plots satisfy power law.

From Figure 4, it can be seen that $B$ decreases with the increase in $R H$ in a nonlinear form. It can also be observe that number mix ratio has the least while volume and mass mix ratios higher and the same. They also satisfy power law.

From Figure 5, it can be seen that $\kappa$ decreases with the increase in $R H$ in almost power law form. It can also be observe that number values mix ratio has the least while volume and mass mix ratios have higher values and the same.

From Figure 6, it can be seen that the plots of $\gamma$ increase with the increase in $R H$ in almost non-linear form, though they can satisfy power law. The plots using mass and volume mix ratios are higher in magnitude compared to number mix ratio.

\subsection{Optical Properties}

From Figure 2, as from $0 \%$ to $90 \% R H$, the optical depth decreases monotonically with wavelengths and increases with the increase in the $R H$ as a result of the hygroscopic growth. But as the $R H$ increases from $95 \%$ to $99 \% R H$ the optical depth the monotonical behavior continue to decrease with respect to wavelength and $R H$. This behavior may be attributed to the dominance of coarse particles, which increases with the increase in 
Table 4. The table of hygroscopic growth factors, effective radii, $B$ (bulk hygroscopicity), $\kappa$ (hygroscopicity) and $\gamma$ (Humidification factor), of the aerosols using mass mix ratio.

\begin{tabular}{ccccccccc}
\hline$R H(\%)$ & 0 & 50 & 70 & 80 & 90 & 95 & 98 & 99 \\
\hline$g f_{\text {mix }}(R H)$ Equation (4) & 1.0000 & 1.5911 & 1.7897 & 1.9702 & 2.3553 & 2.8693 & 3.8031 & 4.7283 \\
$r_{\text {eff }}$ Equation (5) & 0.5641 & 0.7427 & 0.7832 & 0.8141 & 0.8745 & 0.9429 & 1.0604 & 1.1850 \\
B Equation (10) & & 2.0990 & 1.6880 & 1.4834 & 1.2713 & 1.1604 & 1.0911 & 1.0524 \\
$\kappa$ Equation (7) & & 3.0283 & 2.0282 & 1.6619 & 1.3407 & 1.1907 & 1.1021 & 1.0577 \\
$\gamma$ Equation (9) & & -0.6701 & -0.4834 & -0.4213 & -0.3721 & -0.3519 & -0.3415 & -0.3374 \\
\hline
\end{tabular}

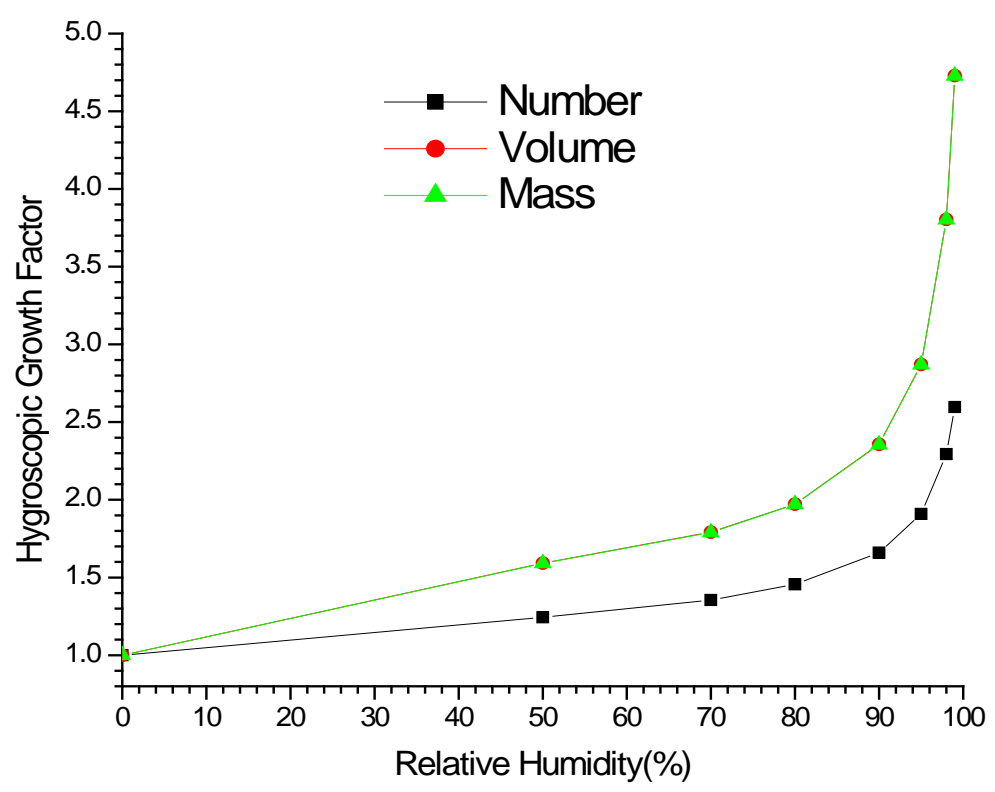

Figure 2. A graph of $g f_{\text {mix }}$ against $R H$ using number, volume and mass mix ratios using the data from Tables 2-4.

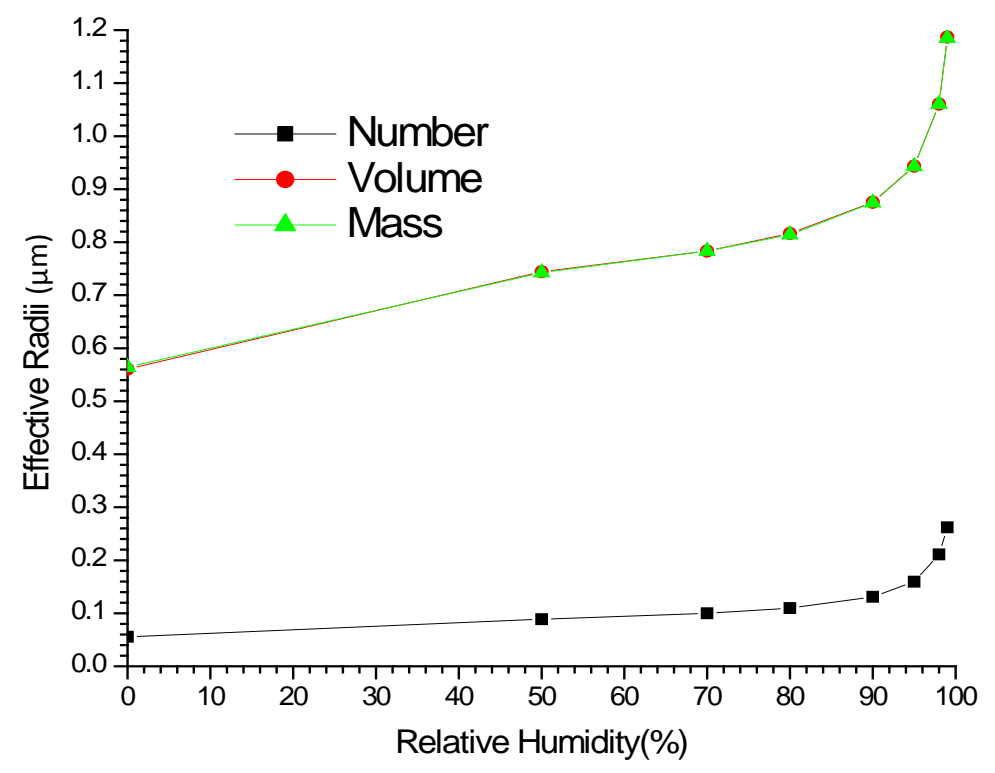

Figure 3. A graph of effective radii against $R H$ using number, volume and mass mix ratios using the data from Tables 2-4. 


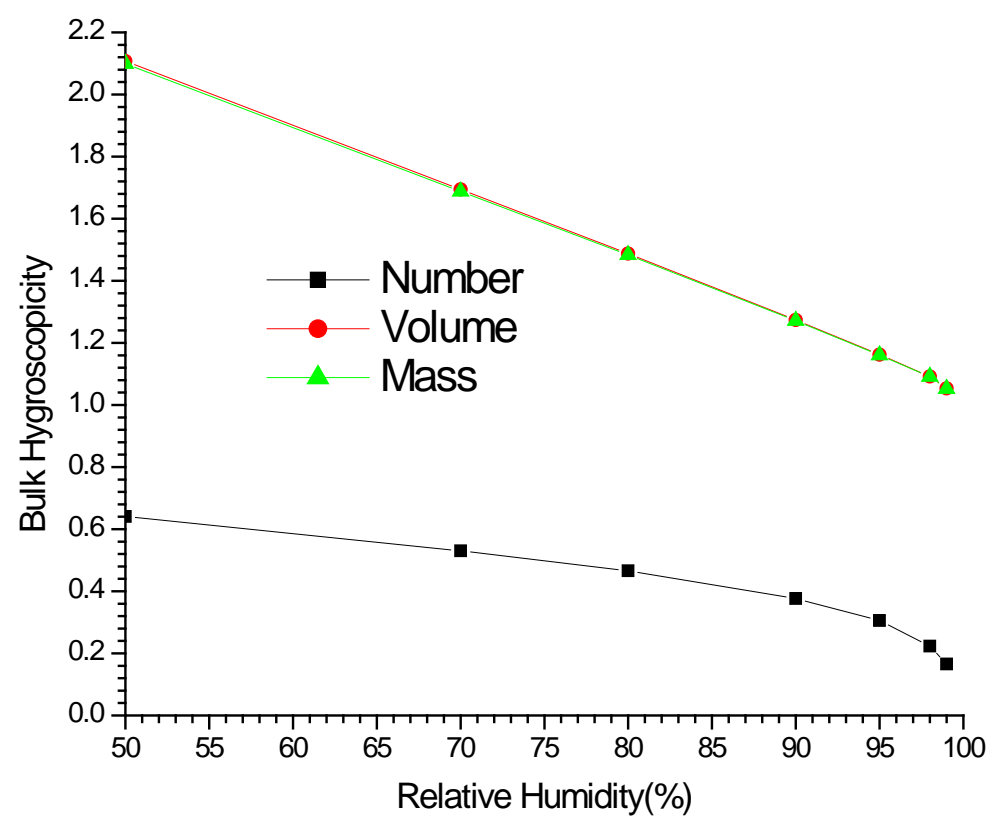

Figure 4. A graph of $B$ (bulk hygroscopicity) against $R H$ using number, volume and mass mix ratiosusing the data from Tables 2-4.

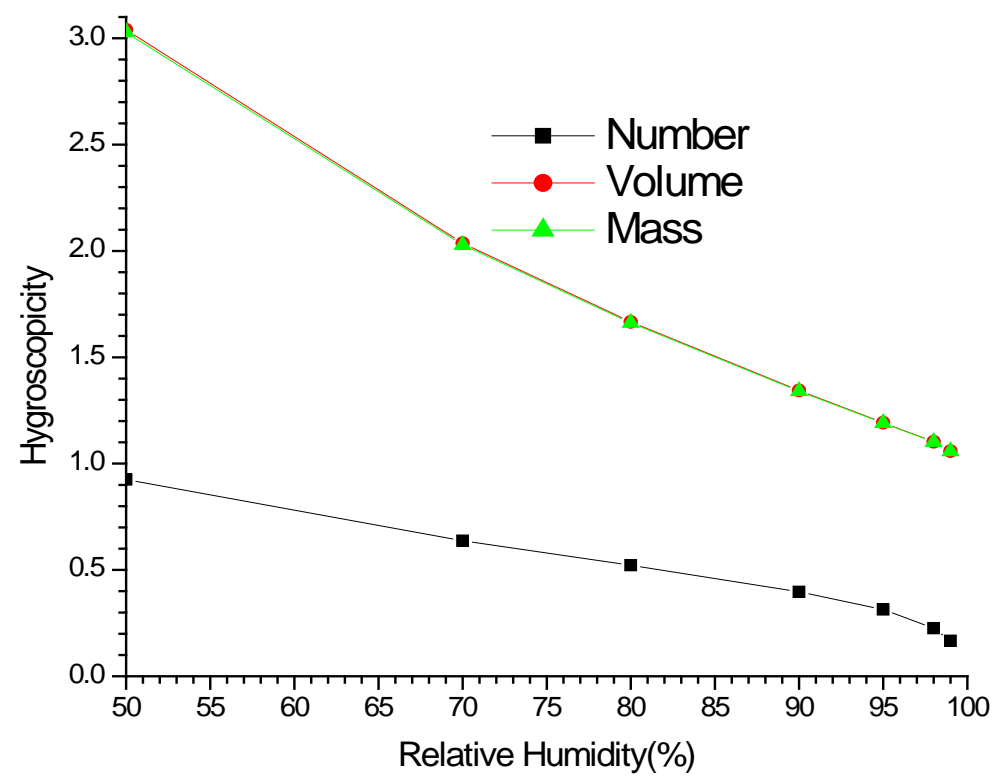

Figure 5. A graph of $\kappa$ (hygroscopicity) against $R H$ using number, volume and mass mix ratios using the data from Tables 2-4.

hygroscopic growth. The behavior of the power law decreases with the increase in $R H$ s, this also signifies the increase in the dominance of coarse particles with the increase in $R H$.

Using the data for plotting Figure 7, the results of exponential relation between optical depth and $R H$ s using Equation (19) are:

At $\lambda=0.25 \mu, A=0.0412, B=1.2079, R^{2}=0.6283$

At $\lambda=1.25 \mu, A=0.0093, B=2.3547, R^{2}=0.7783$

At $\lambda=2.50 \mu, A=0.0029, B=3.2068, R^{2}=0.7800$

The relation between optical depth and $R H$ shows increase in $R^{2}$ and exponent $B$ with the increase in wavelength, and this signifies the dominance of coarse particles. 


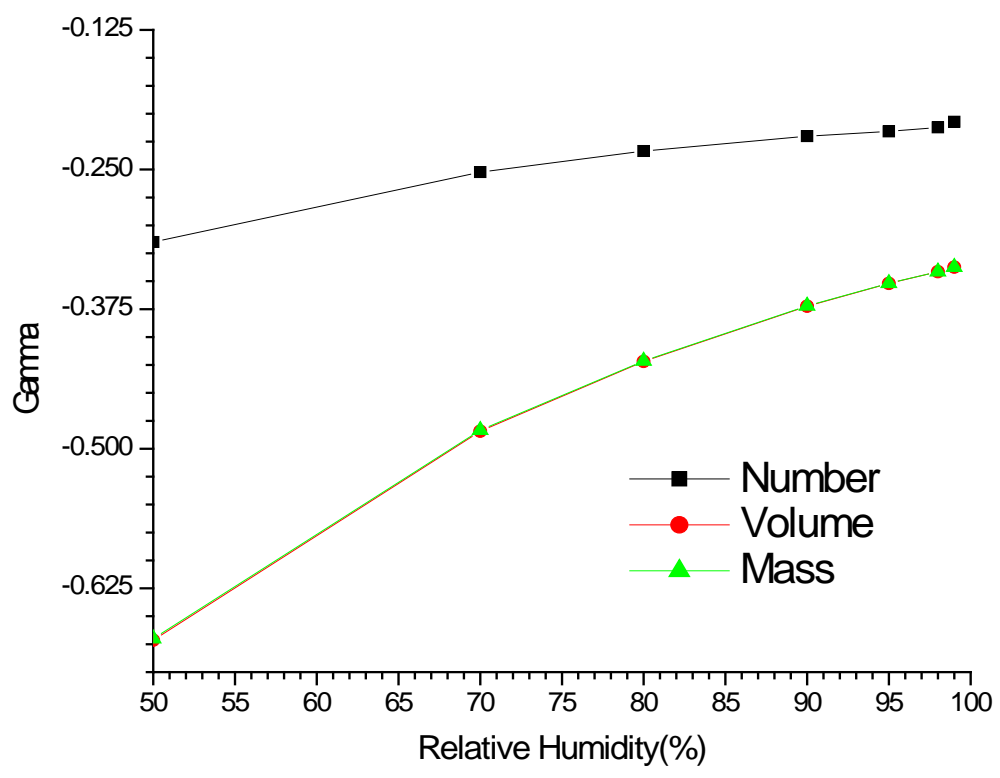

Figure 6. A graph of $\gamma$ against $R H$ using number, volume and mass mix ratios.

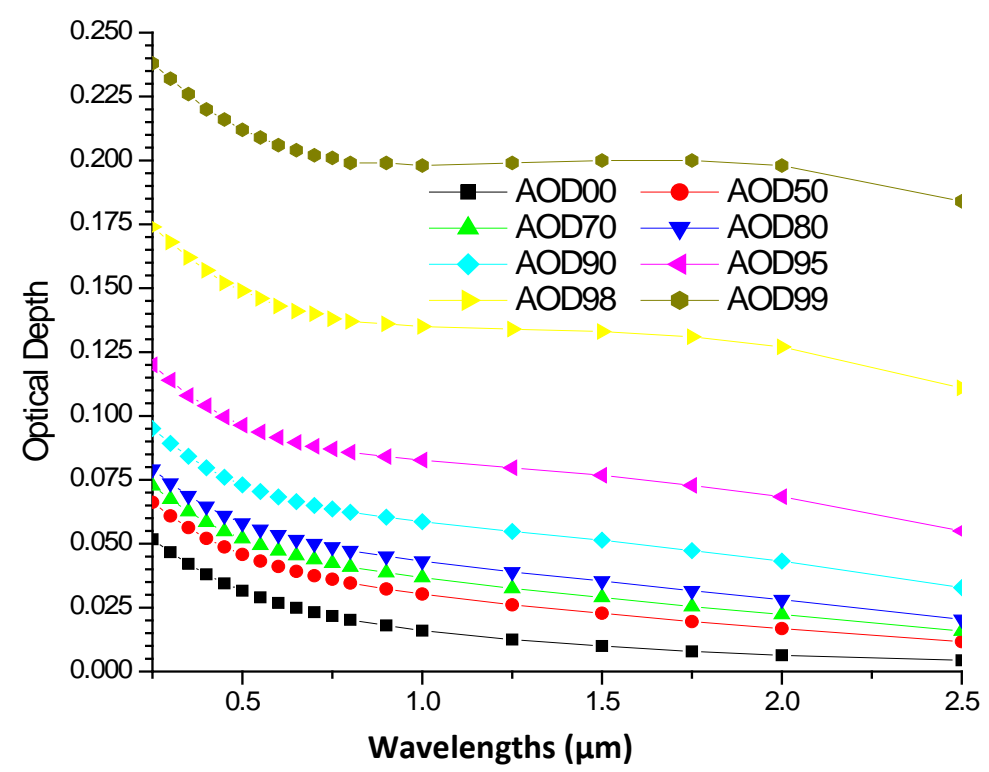

Figure 7. A graph of optical depth against wavelengths.

From Table 5, at $0 \% R H$, the value of $\alpha$ is greater than 1 , and this signifies the dominance of fine particles. But as the $R H$ increases, it continues to decrease signifying the increase in the dominance of coarse particles. From the quadratic part, the negative curvature $\left(\alpha_{2}\right)$ decreases with the increase in $R H$ and became positive and increased further and also the values of $R^{2}$ decreases with the increase in $R H$, and these signify increase in the concentration of coarse particles with the increase in $R H$. The increase in the coarse particle size can be seen in Tables 2-4 where it can be seen that the effective radii increase with the increase in $R H$ s. The cubic part signifies mode distributions as bi-modal with the dominance of coarse particles, because of the decrease in $\alpha 1$.

Figure 8 shows that the enhancement factors increase with the increase in $R H$ and wavelengths in almost power law form. The nature of the increase with the increase in $R H$ and wavelengths reflects the coarse and highly hygroscopic properties of the aerosols.

The results of the fitted curves of Equations (12) and (14) using the data for plotting Figure 8 are presented as follows; 
Table 5. The results of the Angstrom coefficients for optical depth using Equations (16), (17) and (18) at the respective relative humidities using regression analysis with SPSS16 for windows.

\begin{tabular}{ccccccccccc}
\hline \multirow{2}{*}{$R H(\%)$} & \multicolumn{2}{c}{ Linear } & \multicolumn{3}{c}{ Quadratic } & \multicolumn{3}{c}{ Cubic } \\
\cline { 2 - 10 } & $R^{2}$ & $\alpha$ & $R^{2}$ & $\alpha_{1}$ & $\alpha_{2}$ & $R^{2}$ & $\alpha_{1}$ & $\alpha_{2}$ & $\alpha_{3}$ \\
\hline 0 & 0.9783 & 1.0555 & 0.9994 & -1.1611 & -0.2298 & 0.9998 & -1.1273 & -0.2684 & -0.0506 \\
50 & 0.9715 & 0.6917 & 0.9926 & -0.7611 & -0.1510 & 0.9981 & -0.6750 & -0.2493 & -0.1288 \\
70 & 0.9687 & 0.5959 & 0.9882 & -0.6535 & -0.1254 & 0.9969 & -0.5600 & -0.2321 & -0.1399 \\
80 & 0.9666 & 0.5204 & 0.9842 & -0.5683 & -0.1042 & 0.9959 & -0.4732 & -0.2126 & -0.1422 \\
90 & 0.9617 & 0.3941 & 0.9728 & -0.4229 & -0.0628 & 0.9922 & -0.3301 & -0.1687 & -0.1388 \\
95 & 0.9536 & 0.2783 & 0.9562 & -0.2883 & -0.0217 & 0.9856 & -0.2072 & -0.1143 & -0.1213 \\
98 & 0.9165 & 0.1548 & 0.9277 & -0.1431 & 0.0254 & 0.9642 & -0.0918 & -0.0332 & -0.0767 \\
99 & 0.8178 & 0.0885 & 0.9166 & -0.0676 & 0.0456 & 0.9449 & -0.0402 & 0.0144 & -0.0409 \\
\hline
\end{tabular}

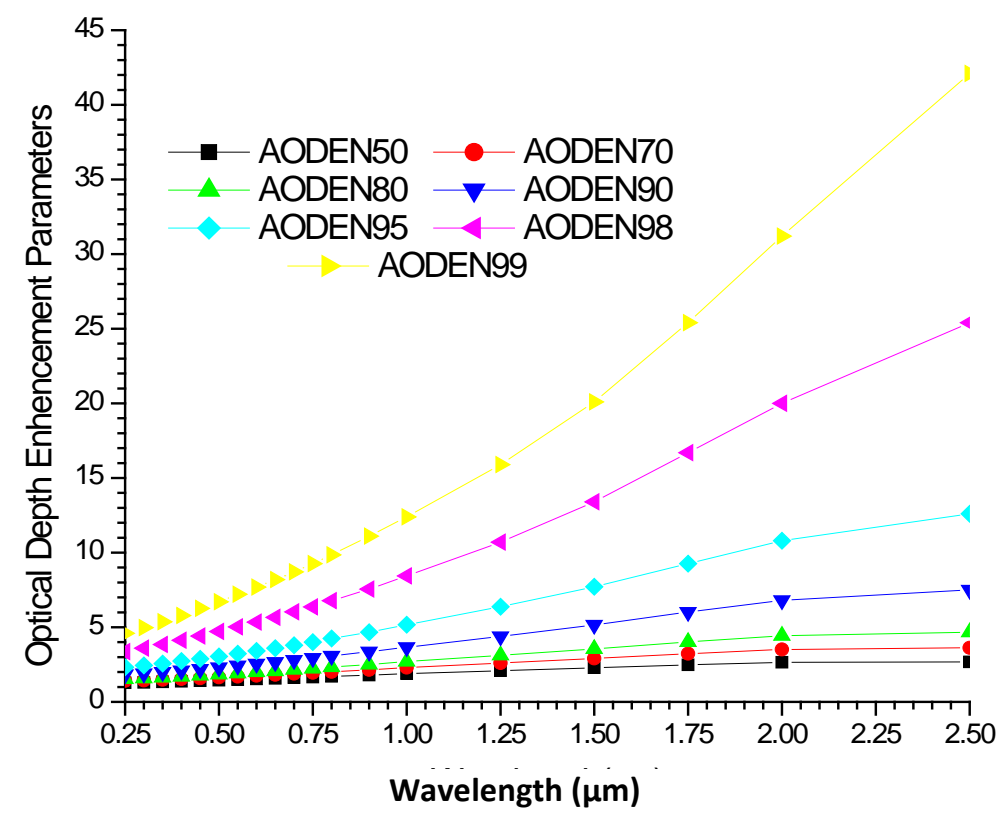

Figure 8. A graph of enhancement parameter for optical depth against wavelengths.

For a single parameter using Equation (12).

At $\lambda=0.25 \mu, \gamma=0.3069, R^{2}=0.9932$

At $\lambda=0.45 \mu, \gamma=0.3783, R^{2}=0.9965$

At $\lambda=0.55 \mu, \gamma=0.4153, R^{2}=0.9970$

At $\lambda=0.70 \mu, \gamma=0.4643, R^{2}=0.9969$

At $\lambda=1.25 \mu, \gamma=0.6233, R^{2}=0.9921$

At $\lambda=2.50 \mu, \gamma=0.8462, R^{2}=0.9925$

For two parameters using Equation (14).

At $\lambda=0.25 \mu, a=0.9326, b=-0.3287, R^{2}=0.9796$

At $\lambda=0.45 \mu, a=0.9900, b=-0.3815, R^{2}=0.9848$

At $\lambda=0.55 \mu, a=1.0298, b=-0.4061, R^{2}=0.9869$

At $\lambda=0.70 \mu, a=1.1075, b=-0.4323, R^{2}=0.9911$

At $\lambda=1.25 \mu, a=1.3781, b=-0.5228, R^{2}=0.9975$ 
At $\lambda=2.50 \mu, a=1.5364, b=-0.7117, R^{2}=0.9985$

For both one and two parameters, the values of $R^{2}$ signify excellent relation and the increase in the exponents signifies increase in relation with wavelength. This signifies the dominance of coarse particles.

Figure 9 shows increase in $\gamma$ with the increase in $R H$ s and wavelengths, and the increase is more significant at higher $\mathrm{RHs}$ and wavelengths. This also shows the dominance of coarse and very hygroscopic particles.

Comparing Figure 7 and Figure 10, it can be seen that they are similar, except that the plots in Figure 7 have higher values.

Using the data for plotting Figure 10, the results of exponential relation between extinction coefficient and $R H$ s using Equation (19) are:

At $\lambda=0.25, A=0.0110, B=2.3400, R^{2}=0.7856$

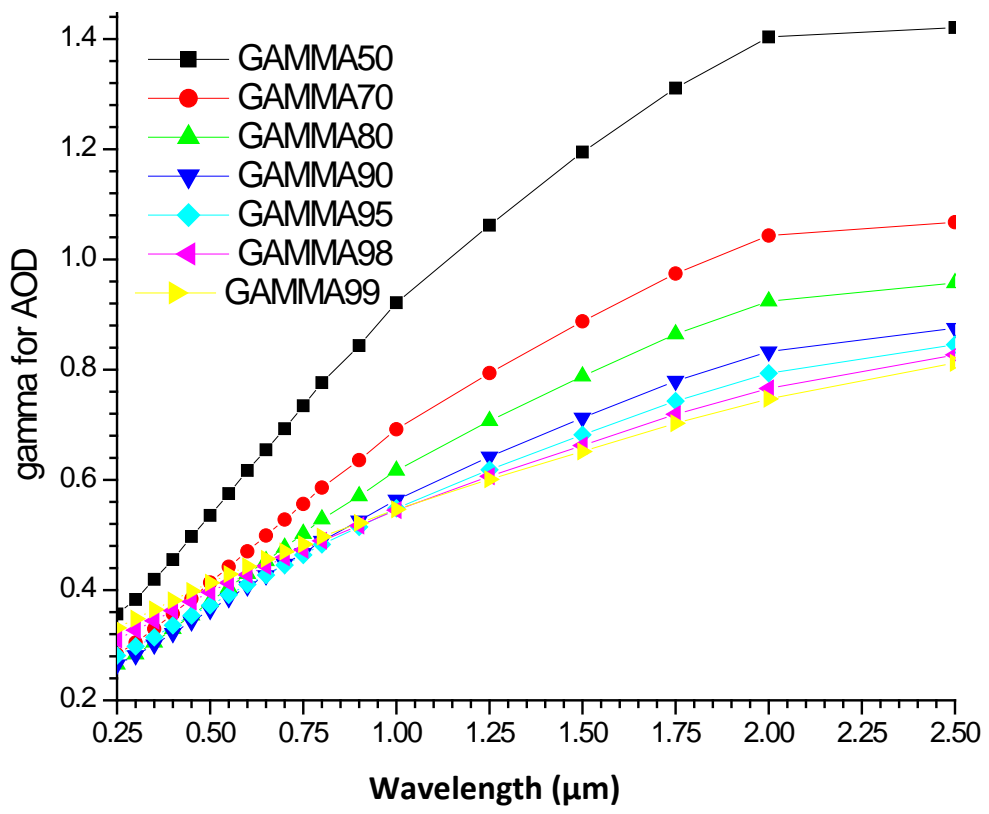

Figure 9. A graph of $\gamma$ against wavelength using Equation (13).

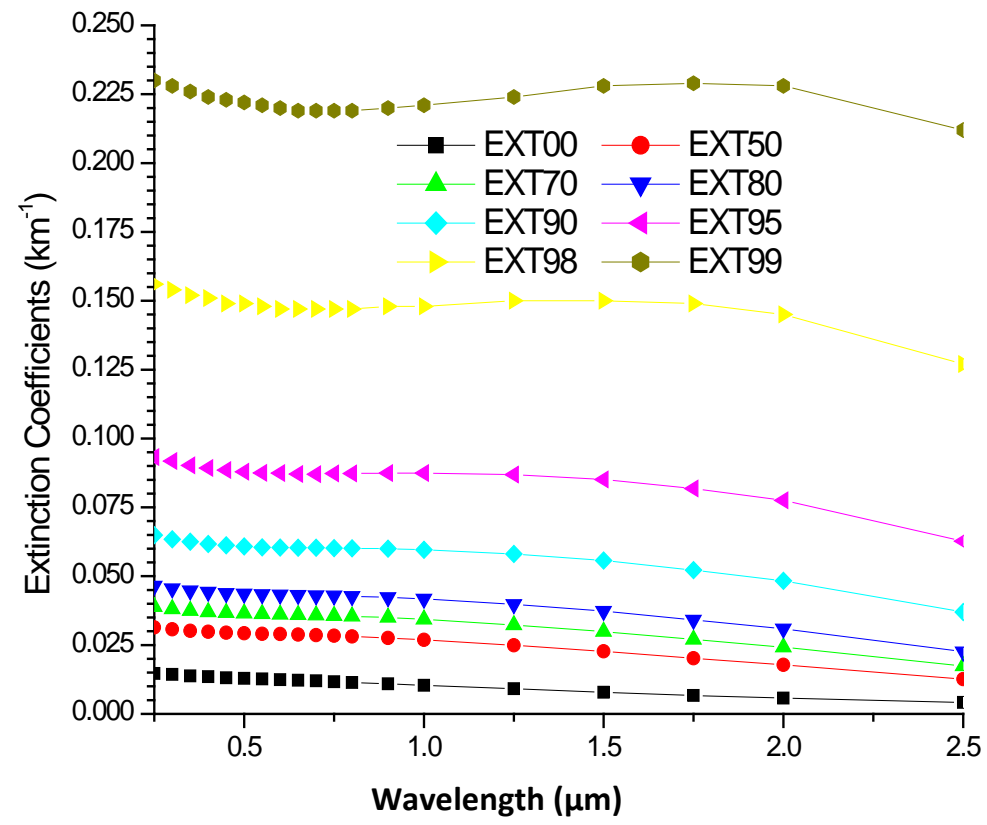

Figure 10. A graph of extinction coefficients against wavelengths. 
At $\lambda=1.25 \mu, A=0.0069, B=2.7675, R^{2}=0.8272$

At $\lambda=2.50 \mu, A=0.0028, B=3.3947, R^{2}=0.8007$

The relation between optical depth and $R H$ shows increase in $R^{2}$ and exponent $B$ with the increase in wavelength, and this signifies the dominance of coarse particles.

At Table 6, from the linear part with the values of $\alpha$ is less than 1 and together with the values of $R^{2}$ continue decreasing with the increase in $R H$ signify the dominance of coarse particles. From the quadratic part, the negative curvature $\left(\alpha_{2}\right)$ decreases with the increase in $R H$ and became positive and increase further and this also signifies increase in the concentration of coarse particles as a result of coagulation, aging and sedimentation of fine particles with the increase in $R H$. This increase can be seen in Tables 2-4 where it can be observe that the effective radii increase with the increase in $R H$ s. The cubic part signifies mode distributions as bi-modal with the dominance of coarse mode particles.

From Figure 11, comparing Figure 8 and Figure 11, it can be observe that they are similar, except that the values of the plots for Figure 11 are higher than those in Figure 8.

Table 6. The results of the Angstrom coefficients for extinction coefficient using Equations (16), (17) and (18) at the respective relative humidities using regression analysis with SPSS16 for windows.

\begin{tabular}{|c|c|c|c|c|c|c|c|c|c|}
\hline \multirow{2}{*}{$R H(\%)$} & \multicolumn{2}{|c|}{ Linear } & \multicolumn{3}{|c|}{ Quadratic } & \multicolumn{4}{|c|}{ Cubic } \\
\hline & $R^{2}$ & $\alpha$ & $R^{2}$ & $\alpha_{1}$ & $\alpha_{2}$ & $R^{2}$ & $\alpha_{1}$ & $\alpha_{2}$ & $\alpha_{3}$ \\
\hline 0 & 0.8566 & 0.4875 & 0.9866 & -0.6168 & -0.2815 & 0.9998 & -0.5165 & -0.3961 & -0.1501 \\
\hline 50 & 0.7329 & 0.3025 & 0.9443 & -0.4131 & -0.2408 & 0.9965 & -0.2790 & -0.3938 & -0.2006 \\
\hline 70 & 0.7062 & 0.2552 & 0.9241 & -0.3518 & -0.2102 & 0.9934 & -0.2190 & -0.3617 & -0.1987 \\
\hline 80 & 0.6828 & 0.2198 & 0.9019 & -0.3045 & -0.1846 & 0.9901 & -0.1734 & -0.3342 & -0.1961 \\
\hline 90 & 0.6427 & 0.1577 & 0.8462 & -0.2181 & -0.1315 & 0.9796 & -0.0988 & -0.2676 & -0.1784 \\
\hline 95 & 0.5851 & 0.1003 & 0.7466 & -0.1362 & -0.0781 & 0.9500 & -0.0380 & -0.1901 & -0.1468 \\
\hline 98 & 0.4311 & 0.0412 & 0.4648 & -0.0491 & -0.0171 & 0.8194 & 0.0130 & -0.0880 & -0.0929 \\
\hline 99 & 0.0641 & 0.0081 & 0.1897 & -0.0004 & 0.0168 & 0.5556 & 0.0317 & -0.0198 & -0.0479 \\
\hline
\end{tabular}

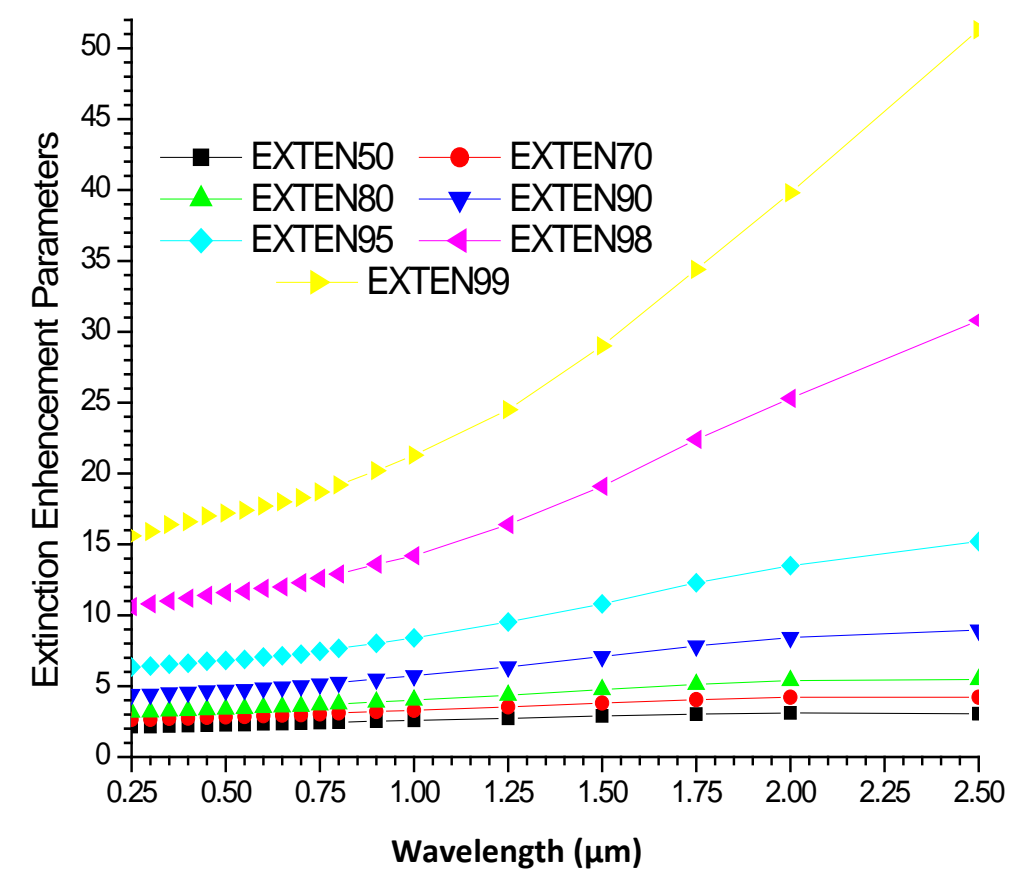

Figure 11. A graph of enhancement parameter for extinction coefficients against wavelengths. 
The results of the fitted curves of Equations (12) and (14) using the data for plotting Figure 11 are presented as follows;

For a single parameter using Equation (12).

At $\lambda=0.25 \mu, \gamma=0.6223, R^{2}=0.9907$

At $\lambda=0.45 \mu, \gamma=0.6429, R^{2}=0.9888$

At $\lambda=0.55 \mu, \gamma=0.6507, R^{2}=0.9883$

At $\lambda=0.70 \mu, \gamma=0.6651, R^{2}=0.9865$

At $\lambda=1.25 \mu, \gamma=0.7461, R^{2}=0.9833$

At $\lambda=2.50 \mu, \gamma=0.9040, R^{2}=0.9891$

For two parameters using Equation (14).

At $\lambda=0.25 \mu, a=1.4203, b=-0.5124, R^{2}=0.9976$

At $\lambda=0.45 \mu, a=1.4879, b=-0.5184, R^{2}=0.9970$

At $\lambda=0.55 \mu, a=1.5093, b=-0.5217, R^{2}=0.9969$

At $\lambda=0.70 \mu, a=1.5770, b=-0.5225, R^{2}=0.9975$

At $\lambda=1.25 \mu, a=1.7773, b=-0.5660, R^{2}=0.9992$

At $\lambda=2.50 \mu, a=1.7491, b=-0.7289, R^{2}=0.9988$

For both one and two parameters, the values of $R^{2}$ signify excellent relation and the increase in the exponents signifies increase in relation with wavelength. This signifies the dominance of coarse particles.

From Figure 12, comparing Figure 9 and Figure 12, it can be seen that they are the similar, except that the values of the plots in Figure 12 are higher.

From Figure 13, comparing Figure 7, Figure 10 and Figure 13, it can be seen that they are similar.

From Figure 14, comparing Figure 8, Figure 11 and Figure 14, it can be observe that they are similar.

Figure 15 shows that absorption is very small at shorter wavelengths, but as from $1.25 \mu \mathrm{m}$ the absorption increases with both wavelengths and $R H$. This shows that the increase in the absorption is more at larger particles and higher wavelengths as the $R H$ increases and this shows that hygroscopic growth has more effect on larger particles. It also shows that power law is not obeyed.

Figure 16 shows that it is almost 1 as from $0.25 \mu \mathrm{m}$ to $1.25 \mu \mathrm{m}$ and is independent of $R H$ and wavelengths, but as from $1.25 \mu \mathrm{m}$ it increases with the increase in wavelength and $R H \mathrm{~s}$ in a non-linear form. This shows the dominance of coarse particles.

Figure 17 shows that hygroscopic growth has caused increase in scattering in the forward direction especially at shorter wavelength and longer wavelengths. Its relation with wavelengths and $R H$ is non-linear. This can be

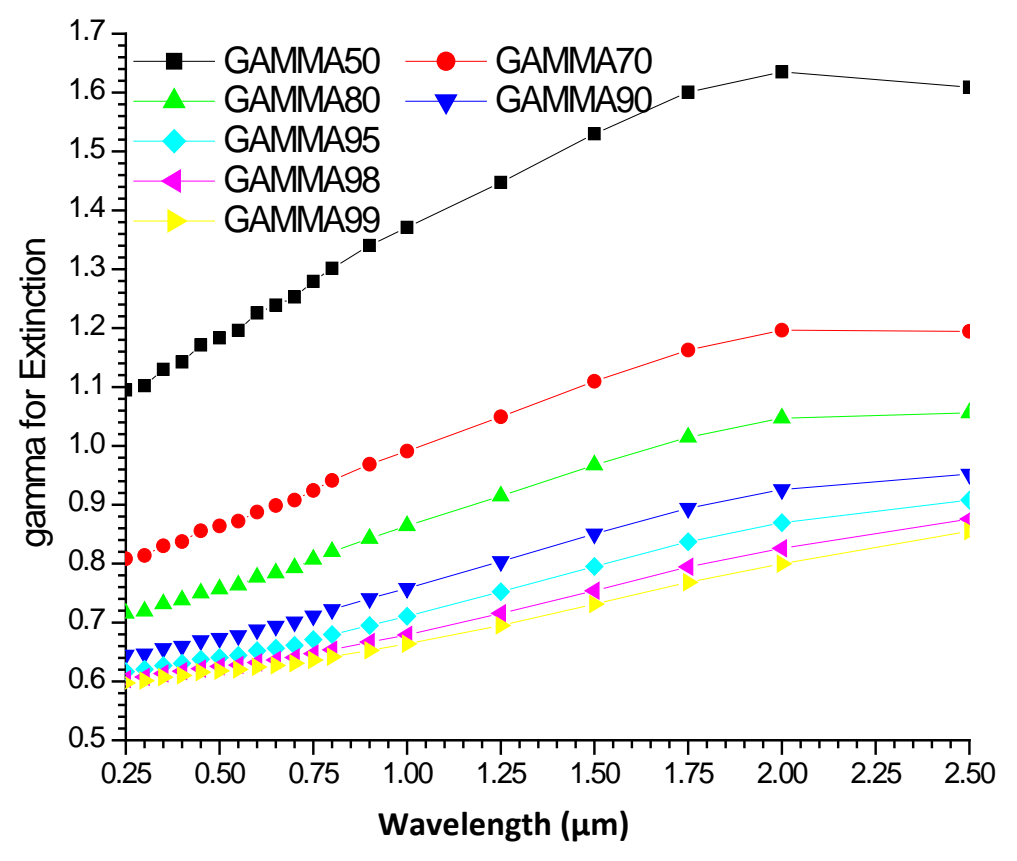

Figure 12. A graph of $\gamma$ against wavelengths using Equation (13). 


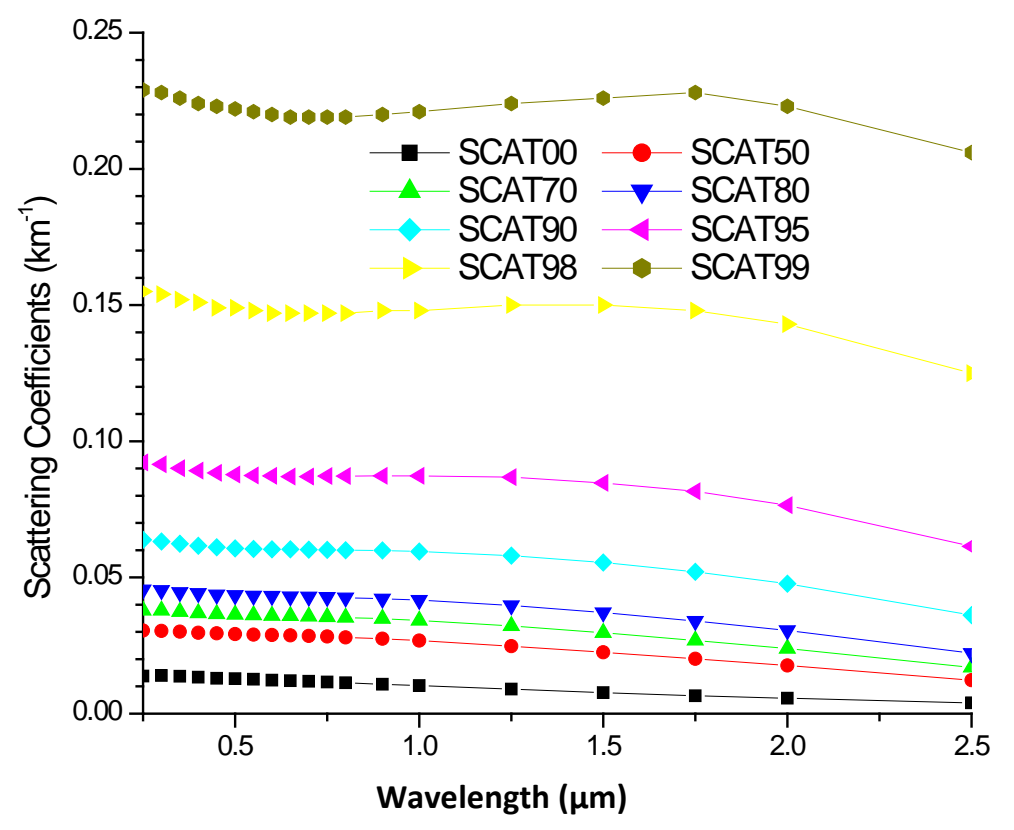

Figure 13. A graph of scattering coefficients against wavelengths.

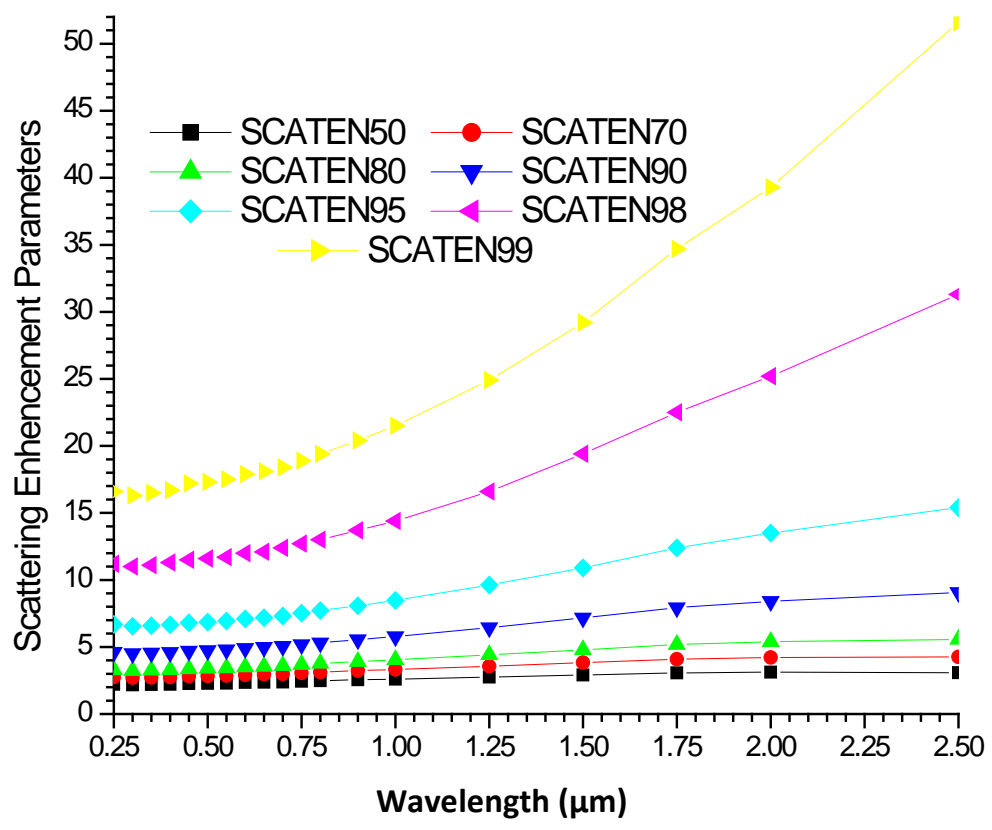

Figure 14. A graph of scattering enhancement against wavelengths.

attributed to high hygroscopicity of these aerosols particles and probably due to internal mixing.

From Figure 18, it can be observe that the plots are non-linear between single scattering albedo with $R H$ and wavelengths. It also shows that as the $R H$ increases, scattering became more dominant at shorter wavelengths while at larger wavelengths, absorptions increases with wavelengths.

\subsection{Effective Refractive Indices}

Figure 19, the non-liner relationship between the real effective refractive indices and wavelengths at $0 \% R H$ signifies the dominance of coarse particles. But as the $R H$ increases, its behaviors with respect to wavelengths and $R H$ s show that the mixtures are internally mixed, probably, because all the particles are very hygroscopic. 


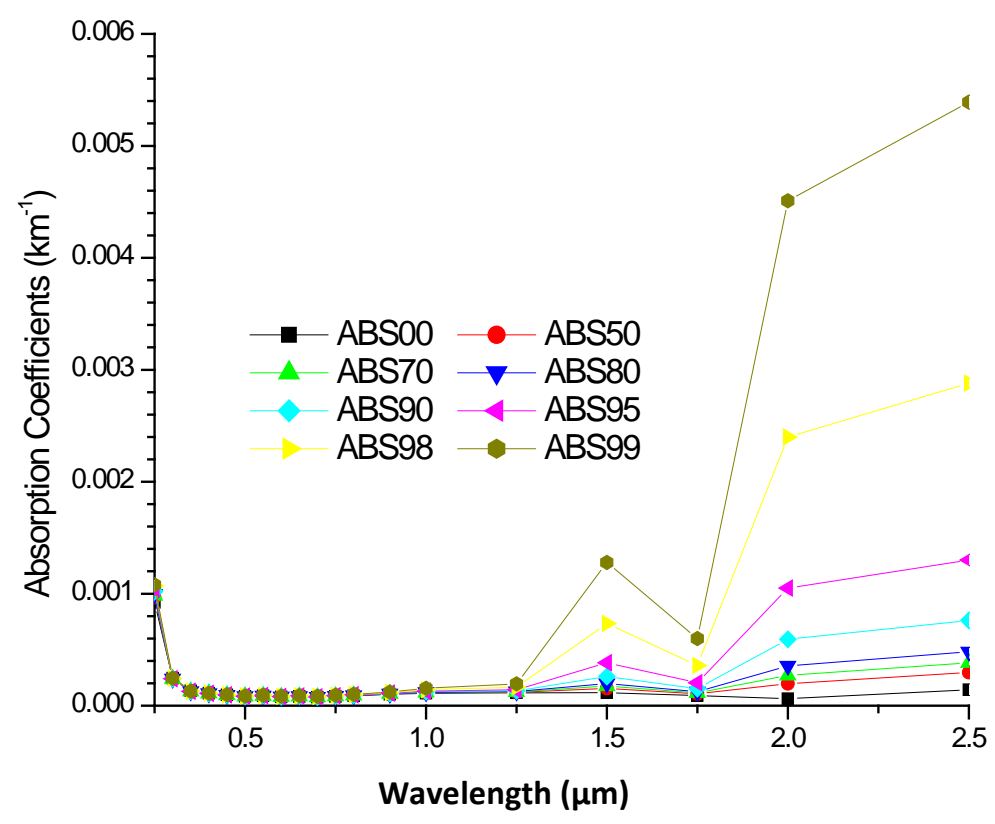

Figure 15. A graph of absorption coefficients against wavelengths.

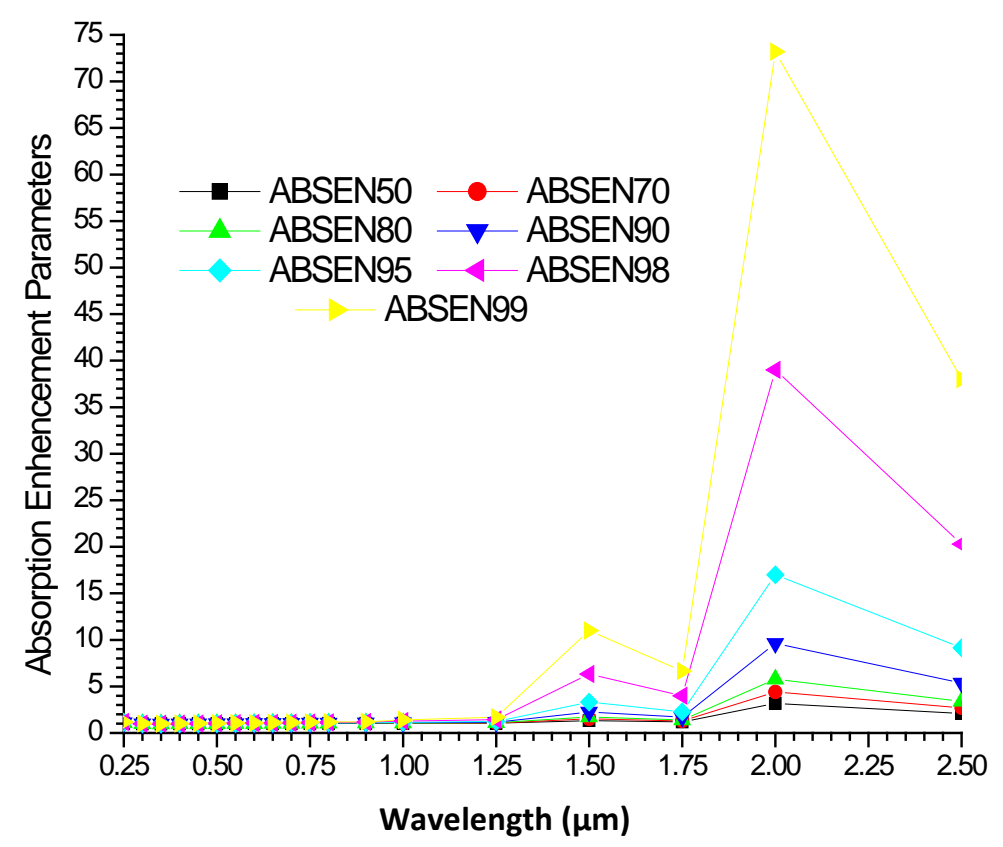

Figure 16. A graph of absorption enhancement against wavelengths.

Figure 20 shows that increase in $R H$ causes decrease in the effective imaginary refractive indices and as the $R H$ increases, its behaviors with respect to $R H$ and wavelengths show that the mixtures are internally mixed, and this maybe because all the aerosols are all very hygroscopic.

From Figure 21, comparing Figure 19 with Figure 21, it can be seen that they are similar.

From Figure 22, comparing Figure 21 with Figure 22, it can be seen that they are similar.

\section{Conclusions}

Comparing the three types of $g f_{\text {mix }}$ obtained, it can be seen that using volume and mass mix ratios gave better representations of the mixture. These also imply that optical effects of atmospheric aerosols are also more 


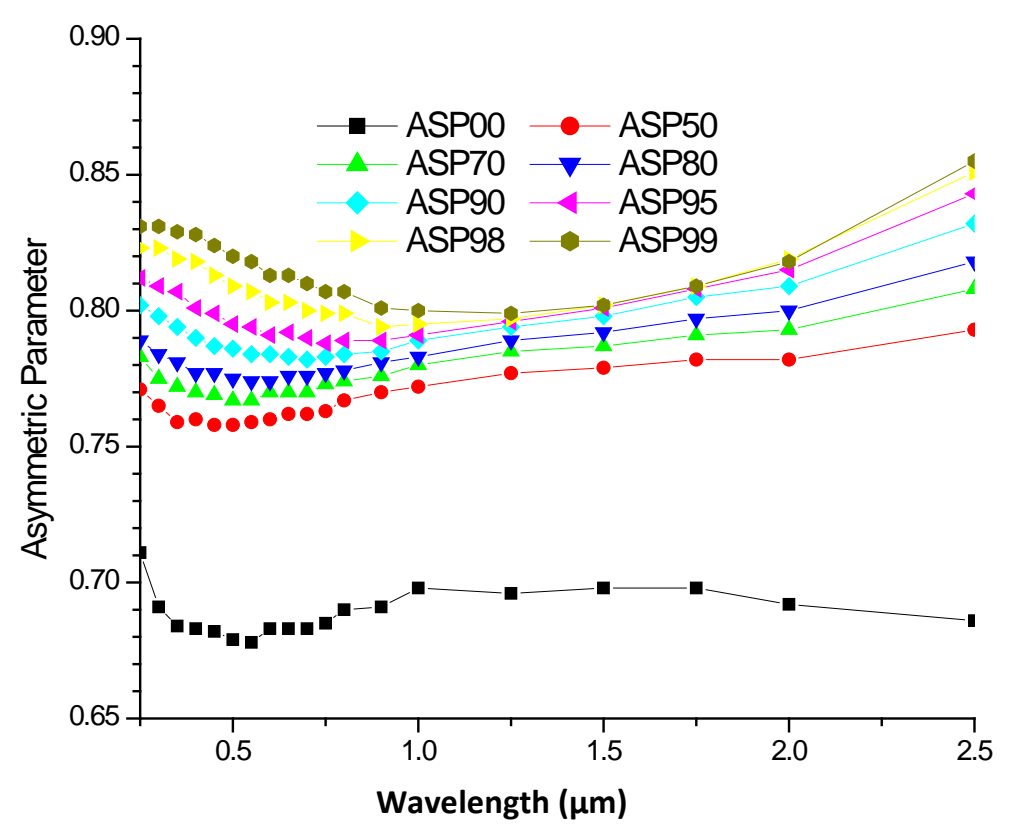

Figure 17. A graph of asymmetric parameter against wavelengths.

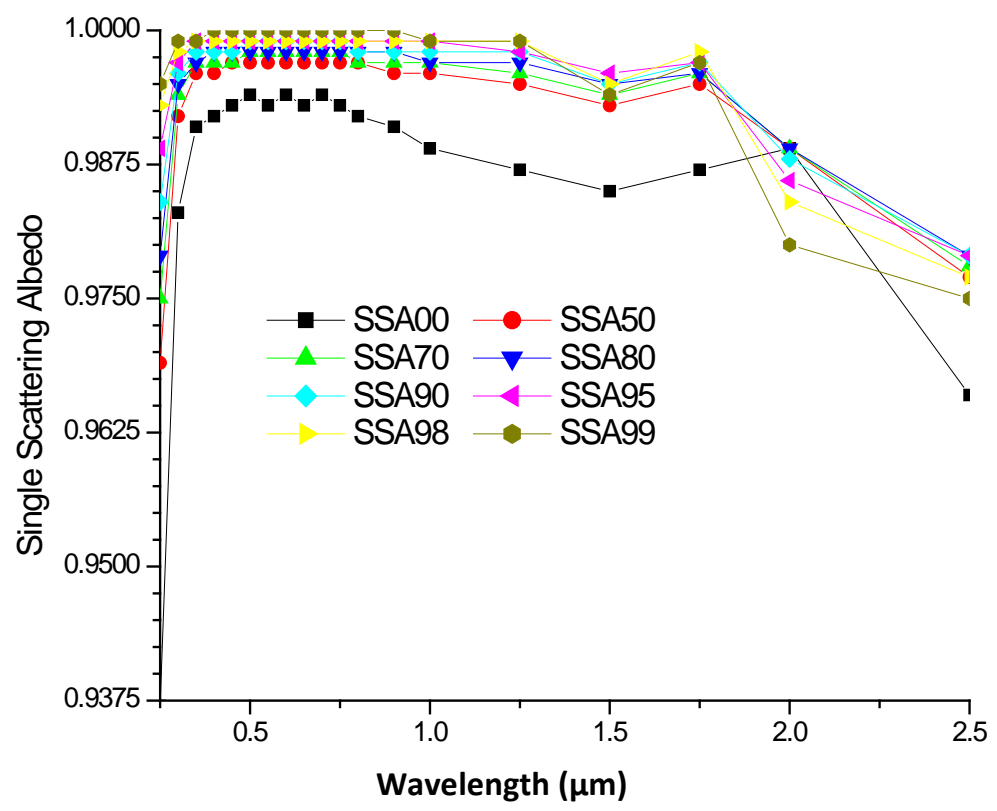

Figure 18. A graph of single scattering albedo against wavelengths.

closely related to their volume than their number [74] [75]. From the $g f_{\text {mix }}(R H)$ observed, it is assumed that the high number fraction of water soluble and sea salt accumulation mode is responsible for its high value. The modeling shows that increase in $R H$ causes decrease in the effective radii, and this is what caused the optical depth and extinction, and scattering coefficients to have higher values at smaller wavelengths with the increase in $R H$ [76]. The relations of these optical and microphysical properties with $R H$ are such that at the deliquescence point (95\% to $99 \%$ ) this growth with higher humidities increases substantially, making this process strongly nonlinear with relative humidity [76]-[78].

This shows that the effective hygroscopic growth in smaller particles reveals an immense potential of light scattering enhancement in the forward scattering [79] while in larger particles it causes increase in the backward scattering at high humidities and the potential for being highly effective cloud condensation nuclei. It also shows 


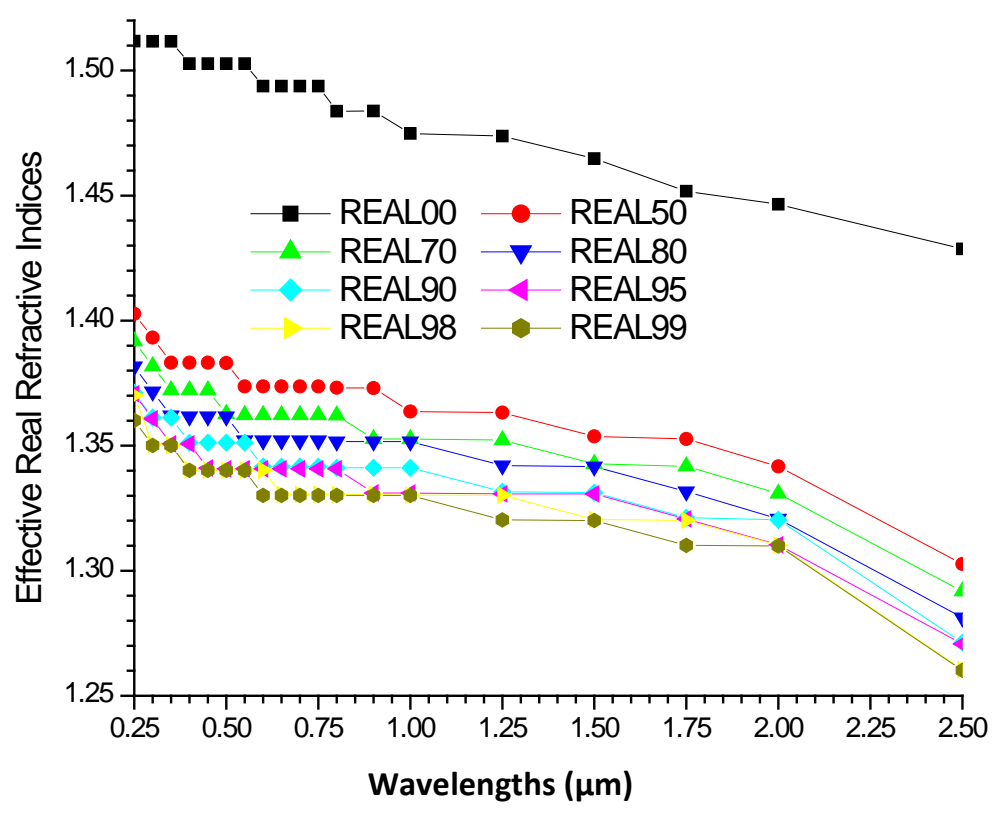

Figure 19. A plot of real effective refractive indices against wavelength using Equation (20).

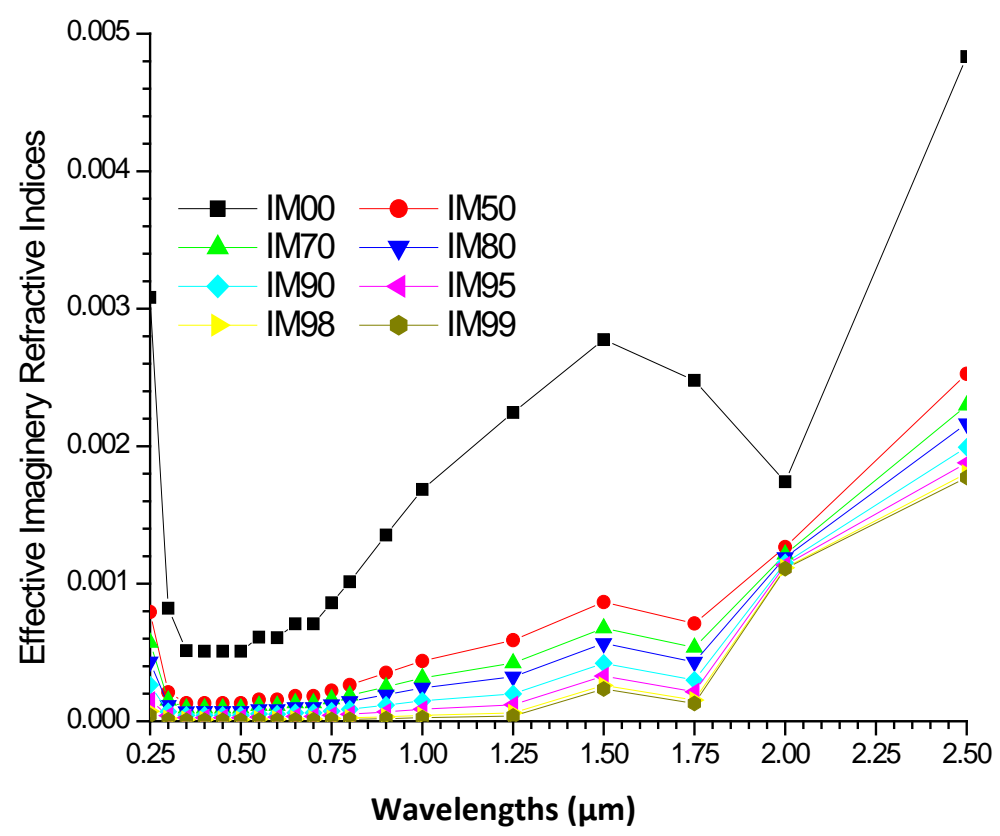

Figure 20. A plot of imaginary effective refractive indices against wavelength using Equation (20).

that the mixture is internally mixed for coarse particles because of the nature of the increase in scattering as a result of the hygroscopic growth [67] and the increase in absorption despite decrease in effective imaginary refractive indices. Therefore, the behavior of internal mixing and the relative importance of the humidity dependences of particle size and index of refraction on the aerosol scattering coefficient for a given substance depend on $R H$ and on the sizes of the particles that provide the dominant contribution to the scattering.

Despite the excellent relation shown for $k$ and $\gamma$ using Equations (6) and (8), but by observing their values using Equations (7) and (9) in Tables 2-4, it can be concluded that the values of these parameters in Equations (6) and (8) could seriously underestimate those of Equations (7) and (8) most especially at lower RHs. Therefore, 


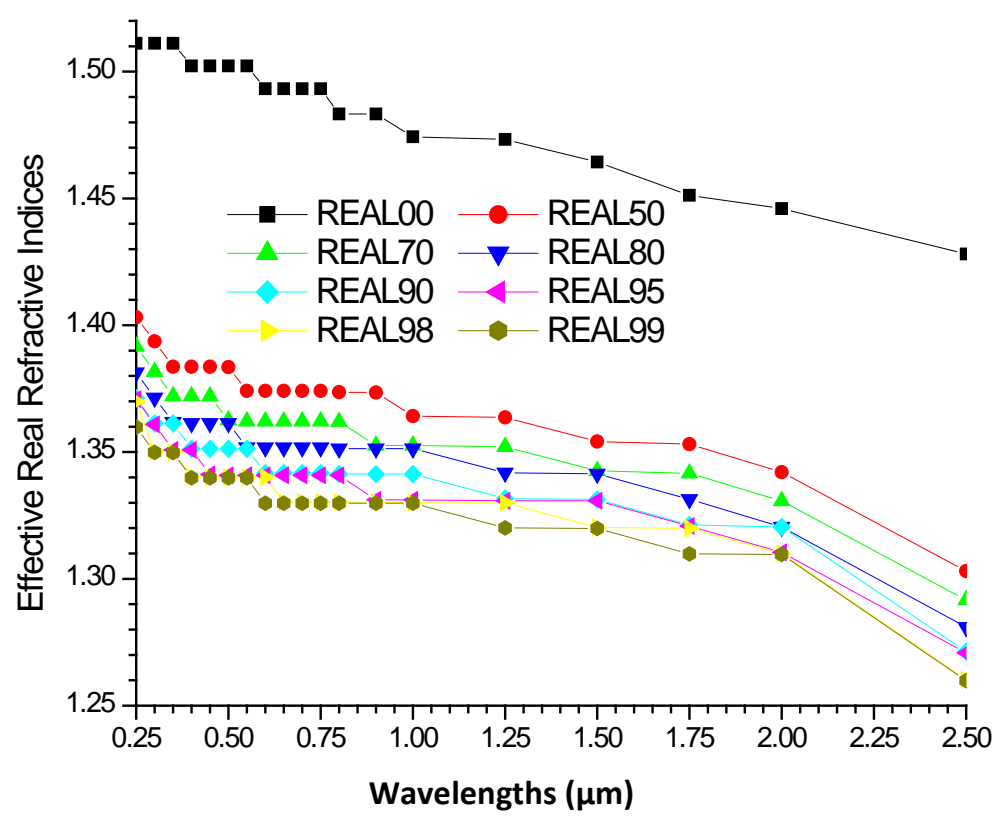

Figure 21. A plot of real effective refractive indices against wavelength using Equation (22).

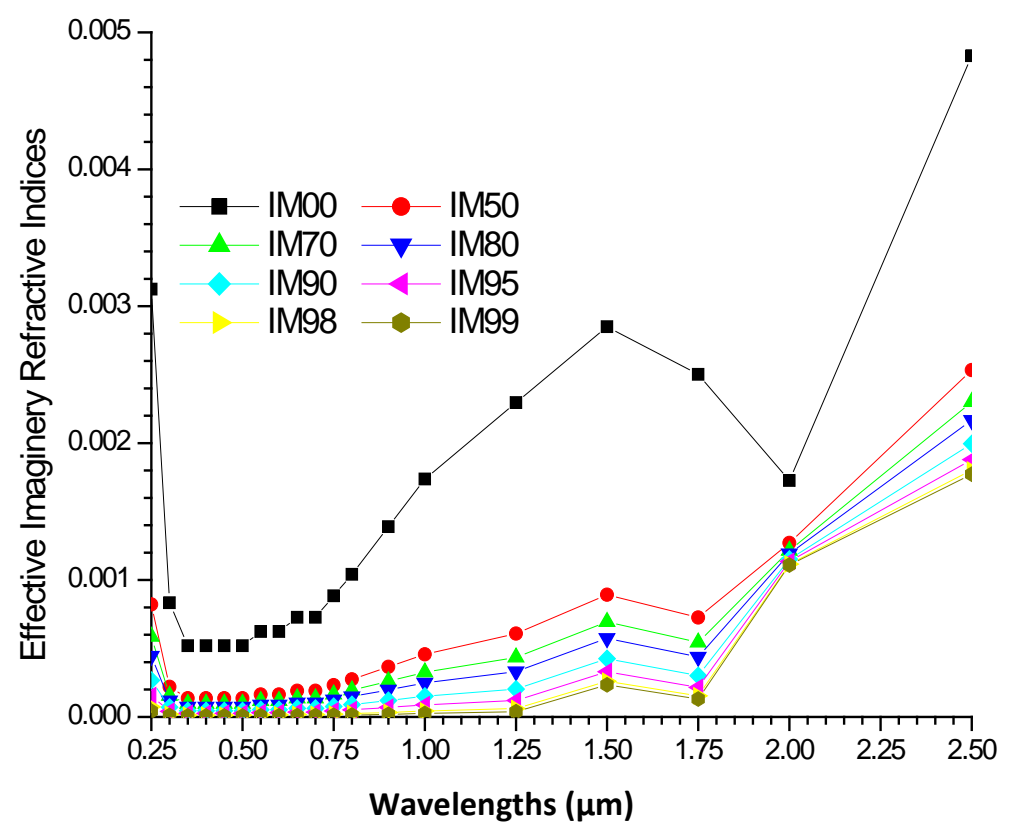

Figure 22. A plot of imaginary effective refractive indices against wavelength using Equation (22).

based on these observations and the observations of hygroscopic parameters in Tables 2-4, it can be concluded that the effective hygroscopic parameters are always dependent on $R H$. The modeling of $g f_{\text {mix }}$ with Equations (6) and (8) shows excellent relation because of the values of $R^{2}$, and all converge to 1 as the $R H$ or $a_{w}$ approaches 0 . The values of $R^{2}$ for Equation (6) are always less than that of Equation (8), and this may be attributed to the kelvin effect of Equation (6) which was neglected, and this shows the influence of Kelvin effect.

From the modeling of the enhancement parameters using Equations (12) and (14), it can be observe that there is a very excellent relation. However, based on convergence the convergence behavior of the two models as $R H$ approaches 0 , it can be seen that Equation (12) is better, because at this limit it approaches 1 , which is what it is 
supposed to be.

Jeong et al. [49] demonstrated an exponential dependence of the aerosol optical thickness on relative humidity. The behavior of exponential relation between optical depth and extinction coefficients with $R H$, shows that it is sensitive to the change in the effective radii. This is because it shows that for smaller particles, the relation is better at shorter wavelengths.

The decrease in the Angstrom coefficients in a non-linear form and the decrease in curvature with $R H$ are in line with the increase in the effective radii with the increase in $R H$. As a consequence of such a non-uniform increase, the Angstrom coefficient also becomes a function of $R H$. The observed variations in Angstrom coefficients can be explained by changes in the effective radii of the mixture resulting from changes in $R H$ : the smaller the number of small aerosol particles, the larger the effective radius and the smaller the Angstrom coefficient. The hygroscopic growth behaviors and the coarse nature of the marine tropical aerosols reveal an immense potential of light scattering enhancement at longer wavelength and at high humidities and the potential for being highly effective cloud condensation nuclei.

Finally, the data fitted our models very well and can be used to extrapolate the hygroscopic growth at any $R H$ and enhancement parameters at any $R H$ and wavelengths. The importance of determining $g f_{\text {mix }}(R H)$ as a function of $R H$ and volume fractions, mass fractions and number fractions, and enhancement parameters as a function of $R H$ and wavelengths can be potentially important because it can be used for efficiently representing aerosolswater interactions in global models.

The refractive index is highly variable depending on the chemical compositions of aerosols and the type of the mixing state [71]. About the two formulas used for the computations of the effective refractive indices, it can be concluded that they are the same, because they gave almost similar plots at the same computational platform.

\section{References}

[1] Cheng, Y.F., Wiedensohler, A., Eichler, H., Heintzenberg, J., Tesche, M., Ansmann, A., Wendisch, M., Su, H., Althausen, D., Herrmann, H., Gnauk, T., Brüggemann, E., Hu, M. and Zhang, Y.H. (2008) Relative Humidity Dependence of Aerosol Optical Properties and Direct Radiative Forcing in the Surface Boundary Layer at Xinken in Pearl River Delta of China: An observation Based Numerical Study. Atmospheric Environment, 42, 6373-6397. http://dx.doi.org/10.1016/j.atmosenv.2008.04.009

[2] Topping, D.O., McFiggans, G.B. and Coe, H. (2005) A Curved Multi-Component Aerosol Hygroscopicity Model Framework: Part 1-Inorganic Compounds. Atmospheric Chemistry and Physics, 5, 1205-1222. http://dx.doi.org/10.5194/acp-5-1205-2005

[3] Topping, D.O., McFiggans, G.B. and Coe, H. (2005) A Curved Multicomponent Aerosol Hygroscopicity Model Framework: Part 2-Including Organic Compounds. Atmospheric Chemistry and Physics, 5, 1223-1242. http://dx.doi.org/10.5194/acp-5-1223-2005

[4] Orr Jr., C., Hurd, F.K. and Corbett, W.J. (1958) Aerosol Size and Relative Humidity. Journal of Colloid Science, 13, 472-482. http://dx.doi.org/10.1016/0095-8522(58)90055-2

[5] Tang, I.N. (1976) Phase Transformation and Growth of Aerosol Particles Composed of Mixed Salts. Journal of Aerosol Science, 7, 361-371. http://dx.doi.org/10.1016/0021-8502(76)90022-7

[6] Twomey, S. (1977) Atmospheric Aerosols. Elsevier, New York.

[7] Ogren, J.A. and Charlson R.J. (1992) Implications for Models and Measurements of Chemical Inhomogeneities among Cloud Droplets. Tellus B, 44, 489-504.

[8] Swietlicki, E., Hansson, H.C., Hameri, K., Svenningsson, B., Massling, A., McFiggans, G., McMurry, P.H., Petaja, T., Tunved, P., Gysel, M., Topping, D., Weingartner, E., Baltensperger, U., Rissler, J., Wiedensohler, A. and Kulmala, M. (2008) Hygroscopic Properties of Submicrometer Atmospheric Aerosol Particles Measured with H-TDMA Instruments in Various Environments: A Review. Tellus B, 60, 432-469. http://dx.doi.org/10.3402/tellusb.v60i3.16936

[9] Rissler, J., Svenningsson, B., Fors, E.O., Bilde, M. and Swietlicki, E. (2010) An Evaluation and Comparison of Cloud Condensation Nucleus Activity Models: Predicting Particle Critical Saturation from Growth at Subsaturation. Journal of Geophysical Research: Atmospheres, 115, Published Online. http://dx.doi.org/10.1029/2010JD014391

[10] Köhler, H. (1936) The Nucleus in and the Growth of Hygroscopic Droplets. Transactions of the Faraday Society, 32, 1152-1161. http://dx.doi.org/10.1039/tf9363201152

[11] Petters, M.D. and Kreidenweis, S.M. (2007) A Single Parameter Representation of Hygroscopic Growth and Cloud Condensation Nucleus Activity. Atmospheric Chemistry and Physics, 7, 1961-1971.

http://dx.doi.org/10.5194/acp-7-1961-2007 
[12] Wex, H., Hennig, T., Salma, I., Ocskay, R., Kiselev, A., Henning, S., Massling, A., Wiedensohler, A. and Stratmann, F. (2007) Hygroscopic Growth and Measured and Modeled Critical Super-Saturations of an Atmospheric HULIS Sample. Geophysical Research Letters, 34, Published Online. http://dx.doi.org/10.1029/2006GL028260

[13] Berg, H.O., Swietlicki, E. and Krejci, R. (1998) Hygroscopic Growth of Aerosol Particles in the Marine Boundary Layer over the Pacific and Southern Oceans during the First Aerosol Characterization Experiment (ACE 1). Journal of Geophysical Research: Atmospheres, 103, 16535-16545.

[14] Swietlicki, E., Zhou, J.C., Covert, D.S., Hameri, K., Busch, B., Väkeva, M., Dusek, U., Berg, O.H., Wiedensohler, A., Aalto, P., Makela, J., Martinsson, B.G., Papaspiropoulos, G., Mentes, B., Frank, G. and Stratmann, F. (2000) Hygroscopic Properties of Aerosol Particles in the Northeastern Atlantic during ACE-2. Tellus B, 52, 201-227. http://dx.doi.org/10.1034/j.1600-0889.2000.00036.x

[15] Maßling, A., Wiedensohler, A., Busch, B., Neusüß, C., Quinn, P., Bates, T. and Covert, D. (2003) Hygroscopic Properties of Different Aerosol Types over the Atlantic and Indian Oceans. Atmospheric Chemistry and Physics, 3, 13771397. http://dx.doi.org/10.5194/acp-3-1377-2003

[16] Andreae, M.O. and Rosenfeld, D. (2008) Aerosol-Cloud-Precipitation Interactions, Part 1. The Nature and Sources of Cloud-Active Aerosols. Earth-Science Reviews, 89, 13-41. http://dx.doi.org/10.1016/j.earscirev.2008.03.001

[17] Gunthe, S.S., King, S.M., Rose, D., Chen, Q., Roldin, P., Farmer, D.K., Jimenez, J.L., Artaxo, P., Andreae, M.O., Martin, S.T. and Pöschl, U. (2009) Cloud Condensation Nuclei in Pristine Tropical Rainforest Air of Amazonia: Size-Resolved Measurements and Modeling of Atmospheric Aerosol Composition and CCN Activity. Atmospheric Chemistry and Physics, 9, 7551-7575. http://dx.doi.org/10.5194/acp-9-7551-2009

[18] Winter, B. and Chýlek, P. (1997) Contribution of Sea Salt Aerosol to the Planetary Clear-Sky Albedo. Tellus B, 49, 7279. http://dx.doi.org/10.1034/j.1600-0889.49.issue1.5.x

[19] Gong, S.L., Barrie, L.A. and Blancbet, J.P. (1997) Modeling Sea-Salts Aerosols in the Atmosphere: 1. Mode1 Development. Journal of Geophysical Research: Atmospheres, 102, 3805-3818. http://dx.doi.org/10.1029/96JD02953

[20] Kammermann, L., Gysel, M., Weingartner, E. and Baltensperger, U. (2010) 13-Month Climatology of the Aerosol Hygroscopicity at the Free Tropospheric Site Jungfraujoch (3580 m a.s.l.). Atmospheric Chemistry and Physics, 10, 10717-10732. http://dx.doi.org/10.5194/acp-10-10717-2010

[21] Pahlow, M., Feingold, G., Jefferson, A., Andrews, E., Ogren, J.A., Wang, J., Lee, Y.N., Ferrare, R.A. and Turner, D.D. (2006) Comparison between Lidar and Nephelometer Measurements of Aerosol Hygroscopicity at the Southern Great Plains Atmospheric Radiation Measurement Site. Journal of Geophysical Research: Atmospheres, 111, Published Online. http://dx.doi.org/10.1029/2004JD005646

[22] Kim, J., Yoon, S.C., Jefferson, A. and Kim, S.W. (2006) Aerosol Hygroscopic Properties during Asian Dust, Pollution, and Biomass Burning Episodes at Gosan, Korea in April 2001. Atmospheric Environment, 40, 1550-1560. http://dx.doi.org/10.1016/j.atmosenv.2005.10.044

[23] Schmidhauser, R., Zieger, P., Weingartner, E., Gysel, M., DeCarlo, P.F. and Baltensperger, U (2009) Aerosol Light Scattering at High Relative Humidity at a High Alpine Site (Jungfraujoch). European Aerosol Conference, Karlsruhe, 6-11 September 2009, Abstract T047A07.

[24] Fierz-Schmidhauser, R., Zieger, P., Vaishya, A., Monahan, C., Bialek, J., O’Dowd, C.D., Jennings, S.G., Baltensperger, U. and Weingartner, E. (2010) Light Scattering Enhancement Factors in the Marine Boundary Layer (Mace Head, Ireland). Journal of Geophysical Research: Atmospheres, 115, Published Online. http://dx.doi.org/10.1029/2009JD013755

[25] Fierz-Schmidhauser, R., Zieger, P., Gysel, M., Kammermann, L., DeCarlo, P. F., Baltensperger, U. and Weingartner, E. (2010) Measured and Predicted Aerosol Light Scattering Enhancement Factors at the High Alpine Site Jungfraujoch. Atmospheric Chemistry and Physics, 10, 2319-2333. http://dx.doi.org/10.5194/acp-10-2319-2010

[26] Zieger, P., Weingartner, E., Henzing, J., Moerman, M., deLeeuw, G., Mikkilä, J., Ehn, M., Petäjä, T., Clémer, K., van Roozendael, M., Yilmaz, S., Frieß, U., Irie, H., Wagner, T., Shaiganfar, R., Beirle, S., Apituley, A., Wilson, K. and Baltensperger, U. (2011) Comparison of Ambient Aerosol Extinction Coefficients Obtained from in-Situ, MAX-DOAS and LIDAR Measurements at Cabauw. Atmospheric Chemistry and Physics, 11, 2603-2624. http://dx.doi.org/10.5194/acp-11-2603-2011

[27] Hess, M., Koepke, P. and Schult, I. (1998) Optical Properties of Aerosols and Clouds: The Software Package OPAC. Bulletin of the American Meteorological Society, 79, 831-844.

[28] Chylek, P. and Wong, J. (1995) Effect of Absorbing Aerosols on Global Radiation Budget. Geophysical Research Letters, 22, 929-931.

[29] Sagan, C. and Pollack, J. (1967) Anisotropic Nonconservative Scattering and the Clouds of Venus. Journal of Geophysical Research: Atmospheres, 72, 469-477. http://dx.doi.org/10.1029/JZ072i002p00469

[30] Penner, J.E., Dickinson, R.E. and O’Neil, C.A. (1992) Effects of Aerosol from Biomass Burning on the Global Radia- 
tion Budget. Science, 256, 1432-1434. http://dx.doi.org/10.1126/science.256.5062.1432

[31] Randles, C.A., Russell, L.M. and Ramaswamy, V. (2004) Hygroscopic and Optical Properties of Organic Sea Salt Aerosol and Consequences for Climate Forcing. Geophysical Research Letters, 31, Published Online. http://dx.doi.org/10.1029/2004GL020628

[32] Sjogren, S., Gysel, M., Weingartner, E., Baltensperger, U., Cubison, M.J., Coe, H., Zardini, A.A., Marcolli, C., Krieger, U.K. and Peter, T. (2007) Hygroscopic Growth and Water Uptake Kinetics of Two-Phase Aerosol Particles Consisting of Ammonium Sulfate, Adipic and Humic Acid Mixtures. Journal of Aerosol Science, 38, 157-171, http://dx.doi.org/10.1016/j.jaerosci.2006.11.005

[33] Stokes, R.H. and Robinson, R.A. (1966) Interactions in Aqueous Nonelectrolyte Solutions. I. Solute-Solvent Equilibria. Journal of Physical Chemistry, 70, 2126-2130. http://dx.doi.org/10.1021/j100879a010

[34] Meyer, N.K., Duplissy, J., Gysel, M., Metzger, A., Dommen, J., Weingartner, E., Alfarra, M.R., Prevot, A.S.H., Fletcher, C., Good, N., McFiggans, G., Jonsson, A.M., Hallquist, M., Baltensperger, U. and Ristovski, Z.D. (2009) Analysis of the Hygroscopic and Volatile Properties of Ammonium Sulphate Seeded and Unseeded SOA Particles. Atmospheric Chemistry and Physics, 9, 721-732. http://dx.doi.org/10.5194/acp-9-721-2009

[35] Stock, M., Cheng, Y.F., Birmili, W., Massling, A., Wehner, B., Müller, T., Leinert, S., Kalivitis, N., Mihalopoulos, N. and Wiedensohler, A. (2011) Hygroscopic Properties of Atmospheric Aerosol Particles over the Eastern Mediterranean: Implications for Regional Direct Radiative Forcing under Clean and Polluted Conditions. Atmospheric Chemistry and Physics, 11, 4251-4271. www.atmos-chem-phys.net/11/4251/2011/ http://dx.doi.org/10.5194/acp-11-4251-2011

[36] Duplissy, J., DeCarlo, P.F., Dommen, J., Alfarra, M.R., Metzger, A., Barmpadimos, I., Prevot, A.S.H., Weingartner, E., Tritscher, T., Gysel, M., Aiken, A.C., Jimenez, J.L., Canagaratna, M.R., Worsnop, D.R., Collins, D.R., Tomlinson, J. and Baltensperger, U. (2011) Relating Hygroscopicity and Composition of Organic Aerosol Particulate Matter. Atmospheric Chemistry and Physics, 11, 1155-1165. http://www.atmos-chem-phys.net/11/1155/2011/ http://dx.doi.org/10.5194/acp-11-1155-2011

[37] Meier, J., Wehner, B., Massling, A., Birmili, W., Nowak, A., Gnauk, T., Brüggemann, E., Herrmann, H., Min, H. and Wiedensohler, A. (2009) Hygroscopic Growth of Urban Aerosol Particles in Beijing (China) during Wintertime: A Comparison of Three Experimental Methods. Atmospheric Chemistry and Physics, 9, 6865-6880.

http://www.atmos-chem-phys.net/9/6865/2009/ http://dx.doi.org/10.5194/acp-9-6865-2009

[38] Sullivan, R.C., Moore, M.J.K., Petters, M.D., Kreidenweis, S.M., Roberts, G.C. and Prather, K.A. (2009) Effect of Chemical Mixing State on the Hygroscopicity and Cloud Nucleation Properties of Calcium Mineral Dust Particles. Atmospheric Chemistry and Physics, 9, 3303-3316. http://dx.doi.org/10.5194/acp-9-3303-2009

[39] Rose, D., Gunthe, S.S., Mikhailov, E., Frank, G.P., Dusek, U., Andreae, M.O. and Pöschl, U. (2008) Calibration and Measurement Uncertainties of a Continuous-Flow Cloud Condensation Nuclei Counter (DMT-CCNC): CCN Activation of Ammonium Sulfate and Sodium Chloride Aerosol Particles in Theory and Experiment. Atmospheric Chemistry and Physics, 8, 1153-1179. http://dx.doi.org/10.5194/acp-8-1153-2008

[40] Poschl, U., Rose, D. and Andreae, M.O. (2009) Climatologies of Cloudrelated Aerosols. Part 2: Particle Hygroscopicity and Cloud Condensation Nuclei Activity. In: Heintzenberg, J. and Charlson, R.J., Eds., Clouds in the Perturbed Climate System: Their Relationship to Energy Balance, Atmospheric Dynamics, and Precipitation, MIT Press, Cambridge, 58-72.

[41] Christensen, S.I. and Petters, M.D. (2012) The Role of Temperature in Cloud Droplet Activation. Journal of Physical Chemistry A, 116, 9706-9717. http://dx.doi.org/10.1021/jp3064454

[42] Niedermeier, D., Wex, H., Voigtländer, J., Stratmann, F., Brüggemann, E., Kiselev, A., Henk, H. and Heintzenberg, J. (2008) LACIS-Measurements and Parameterization of Sea-Salt Particle Hygroscopic Growth and Activation. Atmospheric Chemistry and Physics, 8, 579-590. http://dx.doi.org/10.5194/acp-8-579-2008

[43] Petters, M.D., Wex, H., Carrico, C.M., Hallbauer, E., Massling, A., McMeeking, G.R., Poulain, L., Wu, Z., Kreidenweis, S.M. and Stratmann, F. (2009) Towards Closing the Gap between Hygroscopic Growth and Activation for Secondary Organic Aerosol: Part 2 Theoretical Approaches. Atmospheric Chemistry and Physics, 9, 3999-4009. http://dx.doi.org/10.5194/acp-9-3999-2009

[44] Liu, P.F., Zhao, C.S., Göbel, T., Hallbauer, E., Nowak, A., Ran, L., Xu, W.Y., Deng, Z.Z., Ma, N., Mildenberger, K., Henning, S., Stratmann, F. and Wiedensohler, A. (2011) Hygroscopic Properties of Aerosol Particles at High Relative Humidity and Their Diurnal Variations in the North China Plain. Atmospheric Chemistry and Physics Discussions, 11, 2991-3040. http://dx.doi.org/10.5194/acpd-11-2991-2011

[45] Birmili, W., Nowak, A., Schwirn, K., Lehmann, K., et al. (2004) A New Method to Accurately Relate Dry and Humidified Number Size Distributions of Atmospheric Aerosols. Journal of Aerosol Science, 1, 15-16.

[46] Kasten, F. (1969) Visibility Forecast in the Phase of Pre-Condensation. Tellus, 21, 631-635.

[47] Gysel, M., McFiggans, G.B. and Coe, H. (2009) Inversion of Tandem Differential Mobility Analyser (TDMA) Mea- 
surements. Journal of Aerosol Science, 40, 134-151. http://dx.doi.org/10.1016/j.jaerosci.2008.07.013

[48] Putaud, J.P. (2012) Interactive Comment on “Aerosol Hygroscopicity at Ispra EMEP-GAW Station” by M. Adam et al. Atmospheric Chemistry and Physics Discussions, 12, C200-C202.

[49] Jeong, M.J, Li, Z., Andrews, E. and Tsay, S.C. (2007) Effect of Aerosol Humidification on the Column Aerosol Optical Thickness over the Atmospheric Radiation Measurement Southern Great Plains Site. Journal of Geophysical Research: Atmospheres, 112, Published Online. http://dx.doi.org/10.1029/2006JD007176

[50] Doherty, et al. (2005) A Comparison and Summary of Aerosol Optical Properties as Observed in Situ from Aircraft, ship and Land during ACE-Asia. Journal of Geophysical Research: Atmospheres, 110, Published Online. http://dx.doi.org/10.1029/2004JD004964

[51] Quinn, P.K., et al. (2005) Impact of Particulate Organic Matter on the Relative Humidity Dependence of Light Scattering: A Simplified Parameterization. Geophysical Research Letters, 32, Published Online. http://dx.doi.org/10.1029/2005GL024322

[52] Gassó, S., et al. (2000) Influence of Humidity on the Aerosol Scattering Coefficient and Its Effect on the Upwelling Radiance during ACE-2. Tellus B, 52, 546-567.

[53] Clarke, A., et al. (2007) Biomass Burning and Pollution Aerosol over North America: Organic Components and Their Influence on Spectral Optical Properties and Humidification Response. Journal of Geophysical Research: Atmospheres, 112, Published Online. http://dx.doi.org/10.1029/2006JD007777

[54] Hänel, G. (1976) The Properties of Atmospheric Aerosol Particles as Functions of Relative Humidity at Thermodynamic Equilibrium with Surrounding Moist Air. Advances in Geophysics, 19, 73-188. http://dx.doi.org/10.1016/S0065-2687(08)60142-9

[55] Ångström, A. (1961) Techniques of Determining the Turbidity of the Atmosphere. Tellus, 13, 214-223. http://dx.doi.org/10.1111/j.2153-3490.1961.tb00078.x

[56] King, M.D. and Byrne, D.M. (1976) A Method for Inferring Total Ozone Content from Spectral Variation of Total Optical Depth Obtained with a Solar Radiometer. Journal of the Atmospheric Sciences, 33, 2242-2251. http://dx.doi.org/10.1175/1520-0469(1976)033<2242:AMFITO>2.0.CO;2

[57] Eck, T.F., Holben, B.N., Reid, J.S., Dubovic, O., Smirnov, A., O’Neil, N.T., Slutsker, I. and Kinne, S. (1999) Wavelength Dependence of the Optical Depth of Biomass Burning, Urban and Desert Dust Aerosols. Journal of Geophysical Research: Atmospheres, 104, 31333-31349.

[58] Eck, T.F., Holben, B.N., Ward, D.E., Dubovic, O., Reid, J.S., Smirnov, A., Mukelabai, M.M., Hsu, N.C., O’ Neil, N.T. and Slutsker, I. (2001) Characterization of the Optical Properties of Biomass Burning Aerosols in Zambia during the 1997 ZIBBEE Field Campaign. Journal of Geophysical Research: Atmospheres, 106, 3425-3448. http://dx.doi.org/10.1029/2000JD900555

[59] Eck, T.F., Holben, B.N., Dubovic, O., Smirnov, A., Slutsker, I., Lobert, J.M. and Ramanathan, V. (2001) Column-Integrated Aerosol Optical Properties over the Maldives during the Northeast Monsoon for 1998-2000. Journal of Geophysical Research: Atmospheres, 106, 28555-28566.

[60] Kaufman, Y.J. (1993) Aerosol Optical Thickness and Atmospheric Path Radiance. Journal of Geophysical Research: Atmospheres, 98, 2677-2992. http://dx.doi.org/10.1029/92JD02427

[61] O’Neill, N.T., Dubovic, O. and Eck, T.F. (2001) Modified Ångström Exponent for the Characterization of Submicrometer Aerosols. Applied Optics, 40, 2368-2375. http://dx.doi.org/10.1364/ao.40.002368

[62] O’Neill, N.T., Eck, T.F., Smirnov, A., Holben, B.N. and Thulasiraman, S. (2003) Spectral Dis-Crimination of Coarse and Fine Mode Optical Depth. Journal of Geophysical Research: Atmospheres, 198, Published Online.

[63] Pedrós, R., Martinez-Lozano, J.A., Utrillas, M.P., Gómez-Amo, J.L. and Tena, F. (2003) Column-Integrated Aerosol, Optical Properties from Ground-Based Spectroradiometer Measurements at Barrax (Spain) during the Digital Airborne Imaging Spectrometer Experiment (DAISEX) Campaigns. Journal of Geophysical Research: Atmospheres, 108, Published Online. http://dx.doi.org/10.1029/2002JD003331

[64] Kaskaoutis, D.G. and Kambezidis, H.D. (2006) Investigation on the Wavelength Dependence of the Aerosol Optical Depth in the Athens Area. Quarterly Journal of the Royal Meteorological Society, 132, 2217-2234. http://dx.doi.org/10.1256/qj.05.183

[65] Schmid, B., Hegg, D.A., Wang, J., Bates, D., Redemann, J., Russell, P.B., Livingston, J.M., Jonsson, H.H., Welton, E.J., Seinfeld, J.H., Flagan, R.C., Covert, D.S., Dubovik, O., Jefferson, A., (2003). Column Closure Studies of Lower Tropospheric Aerosol and Water Vapor during ACE-Asia Using Airborne Sun Photometer and Airborne in Situ and Ship-Based Lidar Measurements. Journal of Geophysical Research: Atmospheres, 108, Published Online. http://dx.doi.org/10.1029/2002JD003361

[66] Martinez-Lozano, J.A., Utrillas, M.P., Tena, F., Pedros, R., Canada, J., Bosca, J.V., Lorente, J., (2001) Aerosol Optical Characteristics from Summer Campaign in an Urban Coastal Mediterranean Area. IEEE Transactions on Geoscience 
and Remote Sensing, 39, 1573-1585. http://dx.doi.org/10.1109/36.934089

[67] Aspens, D.E. (1982) Local-Field Effect and Effective-Medium Theory: A Microscopic Perspective. American Association of Physics Teachers, 50, 704-709. http://dx.doi.org/10.1119/1.12734

[68] Heller, W. (1945) The Determination of Refractive Index of Colloidal Particles by Means of a New Mixture Rule or from Measurements of Light Scattering. Physical Review, 68, 5-10. http://dx.doi.org/10.1103/PhysRev.68.5

[69] Wang, J. and Martin, S.T. (2007) Satellite Characterization of Urban Aerosols: Importance of Including Hygroscopicity and Mixing State in the Retrieval Algorithms. Journal of Geophysical Research: Atmospheres, 112, Published Online. http://dx.doi.org/10.1029/2006JD008078

[70] Shettle, E.P. and Fenn, R.W. (1979) Models for the Aerosols of the Lower Atmosphere and the Effects of Humidity Variations on Their Optical Properties. Optical Physics Division, Air Force Geophysics Laboratory, Hanscom Air Force Base, Mass.

[71] D’Almeida, G.A., Koepke, P. and Shettle, E.P. (1991) Atmospheric Aerosols: Global Climatology and Radiative Characteristics. A. Deepak Pub, Hampton, $561 \mathrm{p}$

[72] Lorentz, H.A. (1880) Ueber die Beziehungzwischen der Fortpflanzungsgeschwindigkeit des Lichtes und der Körperdichte. Annalen der Physik, 245, 641-665. http://dx.doi.org/10.1002/andp.18802450406

[73] Lorenz, L. (1880) Ueber die Refractionconstante. Annalen der Physik, 247, 70-103. http://dx.doi.org/10.1002/andp.18802470905

[74] Whitby, K. (1978) The Physical Characteristics of Sulfur Aerosols. Atmospheric Environment, 12, 135-159. http://dx.doi.org/10.1016/0004-6981(78)90196-8

[75] Seinfeld, J.H. and Pandis, S.N. (1998) Atmospheric Chemistry and Physics. Wiley-Interscience Publication, Hoboken.

[76] Kuśmierczyk-Michulec, J. (2009) Ångström Coefficient as an Indicator of the Atmospheric Aerosol Type for a WellMixed Atmospheric Boundary Layer: Part 1: Model Development. Oceanologia, 51, 5-38. http://dx.doi.org/10.5697/oc.51-1.005

[77] Fitzgerald, J.W. (1975) Approximation Formulas for the Equilibrium Size of an Aerosol Particle as a Function of Its Dry Size and Composition and Ambient Relative Humidity. Journal of Applied Meteorology, 14, 1044-1049. http://dx.doi.org/10.1175/1520-0450(1975)014<1044:AFFTES>2.0.CO;2

[78] Tang, I.N. (1996) Chemical and Size Effects of Hygroscopic Aerosols on Light Scattering Coefficients. Journal of Geophysical Research: Atmospheres, 101, 19245-19250. http://dx.doi.org/10.1029/96JD03003

[79] Liou, K.N. (2002) An Introduction to Atmospheric Radiation. Elsevier, New York, 583 p. 